\title{
GESTIÓN ADMINISTRATIVA Y ESTRATÉGICA DE LAS MIPYMES TURÍSTICAS DEL CANTÓN PÉREZ ZELEDÓN, ANTE LAS EXIGENCIAS DE UN MERCADO GLOBALIZADO
}

\author{
EDUARDO MONGE AGUILAR \\ Universidad Estatal a Distancia, Costa Rica \\ emonge@uned.ac.cr
}

\section{RESUMEN}

Se analiza la gestión administrativa y estratégica que emplean las micro, pequeñas y medianas empresas dedicadas a ofrecer servicios turísticos en el cantón de Pérez Zeledón. Este es un cantón con diversidad de empresas orientadas a ofrecer productos y servicios turísticos tanto a la población nacional como a la extranjera. El turismo representa un sector muy importante para el desarrollo económico del país y, por ende, de la Región Sur. Por ello, es relevante analizar el impacto del fenómeno de la globalización en el accionar cotidiano y respuesta del sector a los cambios constantes del entorno. Se deduce, entonces, que todas las empresas, independientemente de su tamaño, ven alterado su actuar debido a la gran cantidad de información que circula en el mercado y a fenómenos provenientes de fuera de las fronteras. Uno de los aspectos que ha sufrido alteraciones debido a la globalización es la forma en que se desenvuelve la competencia empresarial dentro del entorno de un mercado amplio y dinámico. El actual entorno globalizado y competitivo que se vive en el mercado, representa un fuerte impacto para este sector en particular y hace imperiosa la necesidad de que estas empresas cuenten con las herramientas administrativas y estratégicas que les permitan un posicionamiento adecuado dentro de dicho mercado. El estudio realiza un diagnóstico actual de la gestión administrativa y estratégica de las empresas turísticas, con el fin de establecer las debilidades y fortalezas con las que se desarrollan. El objetivo es determinar pasos y recomendaciones a considerar para dar soporte a la gestión y lograr un verdadero crecimiento empresarial. Al concluir la investigación, se brinda una guía clara al microempresario para que establezca prioridades de capacitación, formación y desarrollo de competencias que favorezcan la estabilidad de la empresa, así como desarrollar áreas específicas del negocio y estrategias nuevas de acción. El entorno globalizado hace necesaria una respuesta proactiva de las empresas para lograr competitividad en el mercado.

PALABRAS CLAVE: ALIANZAS ESTRATÉGICAS, CAPACITACIÓN, COMPETENCIAS, CULTURA ORGANIZACIONAL, GERENCIA, GESTIÒN ADMINISTRATIVA, GESTIÓN ESTRATÉGICA, MIPYMET.

\section{ABSTRACT}

It analyzes the administrative and strategic management used by micro, small and medium enterprises, dedicated to offer tourist services in the canton of Perez Zeledon. It is a canton with a diversity of companies oriented to offer tourist products and services to the national as well as foreign population. Tourism represents a very important sector for the economic development of the country and therefore of the South Region. It is therefore important to analyze the impact of the phenomenon of globalization on the daily action and response of the sector to the constant changes in the environment. It 
follows that all companies, regardless of their size, are altered by the large amount of information circulating in the market and phenomena that come from outside the borders. One of the aspects that has suffered alterations due to globalization is the way in which business competition develops, within the environment of a broad and dynamic market. The current globalized and competitive environment in the market represents a strong impact for this particular sector and makes it imperative that these companies have the administrative and strategic tools that allow them to position themselves adequately within that market. The study includes determining a current diagnosis of the administrative and strategic management of tourism companies in order to establish the weaknesses and strengths with which they are developed. The objective is to determine steps and recommendations to consider supporting management and achieving true business growth. At the conclusion of the research, a clear guide is given to the micro entrepreneur to establish training, training and competency development priorities that favor the stability of the company. As well as developing specific areas of the business and new strategies of action. The globalized environment requires a proactive response from companies to achieve market competitiveness.

KEY WORDS: STRATEGIC ALLIANCES, TRAINING, COMPETITIONS, ORGANIZATIONAL CULTURE, MANAGEMENENT, STRATGIC MANAGEMENT, MIPYMET.

\section{INTRODUCCIÓN}

A nivel mundial, el turismo representa una fuerza vital para todas las economías de los países. Cada gobierno debe implementar políticas y estrategias que aseguren que se generen ingresos por medio del turismo nacional. De igual manera, debe existir una estrategia para promover las diferentes atracciones de cada país. Costa Rica es un país privilegiado en naturaleza, con un sin- número sitios de gran belleza y, a nivel mundial, ocupa un puesto significativo como destino turístico.

El actual trabajo pretende estudiar la gestión administrativa y estratégica que siguen o emplean las micro, pequeñas y medianas empresas dedicadas a ofrecer atracciones y servicios turísticos en el cantón de Pérez Zeledón. En este territorio existe gran variedad de empresas que basan su estabilidad económica gracias a los ingresos percibidos por el turismo.

Según la Organización Mundial del Turismo (OMT), el turismo comprende

(...) las actividades que realizan las personas durante sus viajes y estancias en lugares distintos al de su entorno habitual, por un periodo de tiempo consecutivo inferior a un año, con fines de ocio, por negocios y otros motivos no relacionados con el ejercicio de una actividad remunerada en el lugar visitado (Brenes, 2008, p.4).

Entre las pequeñas y medianas empresas turísticas que están instauradas en el cantón de Pérez Zeledón, se pueden citar las siguientes: restaurantes, refugios naturales, parques nacionales, hoteles, lugares de hospedaje, centros de recreación, centros ecológicos y todos aquellos sitios con una oferta de servicios turísticos. Además, los servicios turísticos que generalmente se ofrecen son: alimentación, exhibición de bellezas naturales, hospedajes, caminatas por senderos rodeados de bosque, transporte, pesca deportiva, canopy, observatorios de aves, mariposarios, zonas balnearias, turismo rural, artesanías, cavernas y cataratas, entre otros.

En Costa Rica, gracias a la apertura comercial del país y la existencia de reducidos obstáculos y barreras arancelarias de entrada de nuevas organizaciones, se ha logrado un desarrollo sólido y creciente de la micro, pequeña y mediana empresa. Sin embargo, de igual manera, han 
ingresado y se han instituido grandes empresas transnacionales, las cuales, por su mayor poderío financiero y adquisitivo, logran mayor posicionamiento en el mercado costarricense. Esta desigualdad crea una brecha entre empresas, donde las que no cuentan con recursos se ven perjudicadas y disminuidas en su accionar.

El Gobierno de Costa Rica ha tratado de establecer políticas, estrategias y planes de ayuda a las MIPYMES con el objetivo de dotar a este sector de recursos productivos y financieros que les permita lograr mayor eficiencia operativa y productiva. Pese a esto, estas estrategias no han repercutido positivamente en el logro de resultados preponderantes.

El cantón de Pérez Zeledón cuenta con diversidad de empresas orientadas a ofrecer productos y servicios turísticos a la población nacional y extranjera. Las MIPYMES turísticas de la zona están distribuidas en sus diferentes distritos, lo que garantiza el acceso a ellas. Se aprecia cómo el turismo ha tomado gran importancia para el desarrollo de la Región Sur. Es importante mencionar que, aunque existen muchas micro, pequeñas y medianas empresas en el sector turismo, algunas de ellas funcionan de forma informal.

Una de las mayores atracciones turísticas del cantón, y del país como tal, es la visita al Parque Nacional Chirripó, donde se impone el pico más alto de Costa Rica; donde, además, se aprecia una exuberante belleza escénica a quien lo visita. Pese a esto, el parque no ha impactado sobre un desarrollo sostenible del sector ni del cantón, lo que evidencia la falta de estrategias y planes que permitan un potenciamiento de los recursos existentes. Esto permite que establecer como fundamental el análisis de la gestión desarrollada por este sector económico.

\section{ANTECEDENTES}

Las micro, pequeñas y medianas empresas turísticas, de este punto en adelante: MIPYMET, son pilares en el desarrollo económico nacional de cada país, por ello es fundamental analizar su desempeño. La investigación se realiza con la idea analizar a fondo la forma actual en que las MIPYMET desarrollan su gestión administrativa y estratégica, para luego determinar si estas son las más adecuadas para el buen posicionamiento en el mercado actual y el buen desarrollo en el entorno impactado por la globalización.

La ley 8262 de "fortalecimiento de las pequeñas y medianas empresas", brinda la definición de pyme:

(...) se entiende por pequeña y mediana empresa (PYME) toda unidad productiva de carácter permanente que disponga de los recursos físicos estables y de recursos humanos, los maneje y opere, bajo la figura de persona física o de persona jurídica, en actividades industriales, comerciales o de servicios (MEIC, 2002, p.3).

El Ministerio de Economía Industria y Comercio (MEIC) ha sido el órgano estatal más comprometido con el desarrollo y apoyo a la pequeña y mediana empresa en Costa Rica. Por ello, se solicitó el apoyo a la oficina regional respectiva y se hace uso de la información de esta institución.

Otra referencia acerca de las pymes en Costa Rica es la Política Nacional de Emprendimiento 2010-2014, establecida por el gobierno de la república en cooperación con el Ministerio de Economía, Industria y Comercio. Lo principal de esta política gubernamental es la búsqueda de un "sistema nacional de incubación y aceleración de empresas que propicie y brinde sustento político y técnico a la creación de nuevas empresas, negocios, proyectos e iniciativas productivas, así como el crecimiento de las que inician" (MEIC, 2010, p.1).

Como se analiza más adelante, existen muchos programas, políticas y mecanismos de ayuda hacia las mipymes. Esto, dirige el enfoque en la 
gestión desarrollada por estas empresas, tanto en su manera de administración como en sus estrategias competitivas y de permanencia en el mercado. Costa Rica cuenta con políticas claras y programas de ayuda; sin embargo, es necesario constatar el logro de los objetivos propuestos y si verdaderamente se les está brindando la mano a los sectores desprotegidos de la economía nacional.

Al analizar concepto de turismo, por su importancia para la investigación, se indica que este "es una de las actividades económicas más antiguas y dinámicas que se conocen y todavía rodean al ser humano hoy" (Arce, 2010, p.7). Además, Arce señala que:

El destino turístico es el lugar donde se integran atractivos turísticos, infraestructura, empresas prestatarias de servicios y la superestructura junto al capital humano que desarrolla sus mejores talentos, valores éticos y morales. La finalidad es la producción de servicios con la idea del bienestar común, tanto del turista como del habitante del sitio $(2010$, p.7)

El Instituto Nacional de Estadísticas y Censos (INEC), constantemente se encuentra midiendo los ajustes y modificaciones que acontecen en las empresas a nivel nacional. Basado en la información brindada sobre las instituciones y establecimientos en Costa Rica para el 2012, se obtuvo que las empresas que se enfocan en ofrecer servicios de alojamientos, comercio y comidas son aquellas de micro, pequeño y mediano tamaño, con un número de trabajadores no mayor a 30. El resto de empresas consideradas grandes están mayormente orientadas a labores comerciales y de manufactura, empleando más trabajadores en sus organizaciones (INEC, 2012).

El fenómeno de la globalización ha impactado fuertemente en todos los sectores económi- cos, sociales y políticos de los países mundiales y Costa Rica no se escapa de ello. Se deduce, entonces, que todas las empresas, independientemente de su tamaño, ven alterado su actuar debido a la gran cantidad de información que circula en el mercado y a fenómenos que provienen fuera de las fronteras. Uno de los aspectos que ha sufrido alteraciones debido a la globalización es la forma en que se desenvuelve la competencia empresarial, dentro del entorno de un mercado amplio y dinámico.

Desde este enfoque, las micro, pequeñas y medianas empresas turísticas de Pérez Zeledón, demuestran la necesidad de analizar si tienen las capacidades administrativas y estratégicas para hacer frente al alto grado de competitividad en el mercado presente y las herramientas para transformar sus fortalezas en oportunidades de desarrollo y estabilidad. Esta investigación busca determinar las necesidades de capacitación y entrenamiento de las MIPYMET. Se piensa que las personas que se encuentran laborando en estas organizaciones carecen de actitudes y capacidades emprendedoras. Para implementar un desarrollo continuo de las empresas es indispensable que los trabajadores cuenten con una etapa de capacitación y adiestramiento; sobre todo, se debe inculcar un pensamiento dinámico en su actuación.

Con respecto a la realidad del sector de las mipymes, se asegura que "el 95\% del parque empresarial corresponde a Pymes, de las cuales, por tamaño el 74\% son micro, el $12 \%$ pequeñas y $14 \%$ medianas y, por sector, un $83 \%$ corresponden a servicios y comercio" (MEIC, 2013). El estudio del MEIC proporciona datos acerca del tipo de empresas que predominan en la Región Brunca, "microempresas (78,3\%) y con magnitudes bastante menores están las empresas pequeñas (19,2\%). Tanto las empresas medianas $(2,3 \%)$ como las grandes $(0,2 \%)^{\prime \prime}$ (MEIC, 2012, p.25). 
Otro dato importante de tomar en cuenta, y que sustenta el interés de la presente investigación, es que el $47 \%$ del total de la mipymes de la Región Brunca están dedicadas a la actividad de servicios. Además, del total de empresas involucradas en el estudio del MEIC, estas proporcionan una generación de empleo del 45\% (MEIC, 2013).

Muchas veces las MIPYMET, compiten de una forma que no les genera buenos rendimientos. Este aspecto mejoraría al establecer alianzas estratégicas con otros sectores o con empresas similares. Dichas alianzas estratégicas permitirán contar con las herramientas adecuadas para lograr un posicionamiento eficaz y efectivo en el mercado nacional, adquiriendo la fidelidad de sus clientes.

El observatorio de la UNED sobre las mipymes realizó un estudio sobre el estado actual de este sector. Algunas de las ideas principales son: que el surgimiento de la economía del conocimiento representa nuevos obstáculos, sobre todo en el acceso a las tecnologías de la información y comunicación (TICS) y en el desarrollo de capacidades del recurso humano. El ingreso de actores como China, India y países de Europa alteran las posibles estrategias para el logro de ventajas comparativas. Como último aspecto, la globalización crea riesgos de crisis, lo que hace más vulnerable a las mipymes costarricenses (UNED, 2012).

Las micro, pequeñas y medianas empresas carecen de formación empresarial; muchas de estas organizaciones inician operaciones sin tener ideas claras de cómo lograr sus objetivos, razón que las convierte en fáciles presas de la competencia. Se requiere de una inducción en formación empresarial, en su valor agregado y su importancia para el buen caminar de las empresas.

Un estudio desarrollado por la oficina regional del Ministerio de Economía, sobre las pymes, evidencia otros detalles problemáticos del sector. Estos son:

(...) el bajo crecimiento de la empresariedad local, así como la falta de preparación para vincularse con industrias nacientes, como, por ejemplo, la del sector turismo, ya sea como persona empresaria o empleado calificado, acentuó la problemática. A esto hay que sumarle que, entre los problemas más relevantes de las MIPYMES de la zona, están las barreras para recibir servicios financieros y acompañamiento técnico en el desarrollo de nuevas iniciativas empresariales, la falta de una mayor vinculación entre productores y empresas, así como la necesidad de crear mayores iniciativas micro-empresariales que puedan ser parte del desarrollo sostenible de la región (MEIC, 2012, p.7).

Estos estudios nacionales vienen a generar la necesidad de plantear una propuesta a estas pequeñas organizaciones, donde se contemplen sus verdaderas necesidades y se ajuste a sus requerimientos y exigencias. Se ha analizado el papel de las mipymes en general; sin embargo, a nivel de empresas turísticas, existe poca documentación al respecto.

Un antecedente importante de hacer notar es la inestabilidad económica que sufre el cantón de Pérez Zeledón. Según el informe de la encuesta de establecimiento (2012) del Ministerio de Economía, la Región Brunca "es una de las zonas más pobres y desiguales del país, pese a que posee una rica biodiversidad y un tejido social muy amplio y, por consiguiente, un alto potencial para ser desarrollada" (MEIC, 2012, p.7).

Los datos anteriormente señalados sobre la realidad económica del cantón, justifican la realización de la investigación sobre el papel que trazan las MIPYMET. La necesidad de esta- 
bilidad y desarrollo de la pequeña y mediana empresa en Pérez Zeledón es vital para obtener un cambio en el panorama vivido. Se debe mejorar la capacidad administrativa y estratégica para impactar verdaderamente en el crecimiento global del cantón.

En la semana de la pyme, el MEIC brindó resultados de un estudio sobre la situación de las pymes. Uno de los datos más relevantes fue asegurar que "Las micro, pequeñas y medianas empresas del país tienen un peso del 30\% en el Producto Interno Bruto (PIB) nacional" (MEIC, 2013). Esta información acerca del gran aporte de las mipymes al producto interno bruto del país, brinda una clara perspectiva del grado de importancia que radica en que se preste atención especializada a sus necesidades. Para la economía nacional y el desarrollo empresarial de las pymes es fundamental contar con nuevas herramientas y mecanismo de ayuda y colaboración que aseguren su competitividad y su permanencia en el mercado.

\section{JUSTIFICACIÓN}

Sin lugar a dudas, en la actualidad ha tomado una mayor relevancia el estudio enfocado hacia la micro, pequeña y mediana empresa en Costa Rica. Se ha logrado determinar que estas son un sostén valioso para el desarrollo económico y social. Las MIPYMES se han caracterizado por ser generadoras de ingresos sólidos para el país y de empleos para la población costarricense.

Este sector económico se ha distinguido por trabajar con poco recurso económico, humano y financiero. El aporte que da al gobierno no le es retribuido de la misma manera; el apoyo recibido no es el deseado $y$, muchas veces, se percibe que se le da la espalda. El actual entorno globalizado y competitivo que se vive en el mercado representa un fuerte impacto para este sector en particular y hace imperiosa la necesidad de que estas empresas cuenten con las herramientas administrativas y estratégicas que les permita un posicionamiento adecuado dentro de dicho mercado.

Si las empresas nacionales carecen de ventajas competitivas sobre sus productos y servicios no lograrán mantener una competitividad adecuada ante aquellas internacionales que ingresan al país o que tienen representación por medio de las importaciones de bienes y servicios. La poca adaptabilidad de las micro y pequeñas empresas ante el impacto globalizador hace que estas se vuelvan inestables y con cierto grado de obsolescencia, ocasionando la desmotivación de los pequeños empresarios y la futura quiebra. El impacto de las grandes organizaciones que han iniciado operaciones en el país, la poca transferencia de información y conocimiento, poca capacitación, las limitaciones de mano de obra, la falta de liquidez, poco acceso a la tecnología, reducido acceso a créditos, pobre infraestructura y poco personal, son algunas de los problemas que las MIPYMES deben sobrepasar para lograr un posicionamiento aceptable en el mercado competitivo de servicios.

Como otro punto, la investigación debe analizar si la nueva carretera por la costanera Sur del País ha repercutido en el desarrollo de la micro, pequeña y mediana empresa turística del cantón de Pérez Zeledón. Esto porque se han escuchado ejemplos de lugares que han visto reducidos sus ingresos por causa de estas carreteras, ya que se reporta que cortan el tiempo de recorrido pero que, en este afán, se despreocupan de las personas que viven en zonas que la misma carretera aísla y borra como destino común.

Es muy importante lograr identificar las necesidades actuales de las MIPYMES, para transformarlas en oportunidades de desarrollo. Los programas establecidos por órganos gubernamentales a veces no se basan $100 \%$ en la 
realidad de las empresas. Por esta razón, este estudio espera observar cuáles son las herramientas estratégicas que se requieren para que estas organizaciones diferenciadas logren su consolidación. Para el cantón de Pérez Zeledón, las MIPYMES representan una verdadera fuente de empleo para la población del territorio.

A nivel nacional y regional existen estudios sobre el estado actual de las MIPYMES y unos pocos de ellos sobre el sector turismo. De forma enfocada al territorio de la zona Sur no hay conocimiento de que exista una investigación sobre las empresas dedicadas a la oferta de servicios turísticos que haya estado orientada a analizar su gestión actual y las estrategias que se emplean para competir.

Se sabe que la mayoría de las empresas grandes y consolidadas en la actualidad iniciaron sus operaciones productivas con pocos recursos, infraestructura y capital y solo gracias al establecimiento de ventajas competitivas se han fortalecido con el tiempo. En el caso particular de las empresas de reducido tamaño de Pérez Zeledón, vale la pena hacer notar que la mayoría son de comercio y productivas (agrícolas) a baja escala. Estas se caracterizan por tener una reducida innovación, prácticamente producen según las necesidades del mercado que atienden, que normalmente es el mercado local o regional. Asimismo, no cuentan con una mentalidad de exportación, muchas veces por temor o desinformación del proceso.

Se considera que estas empresas no poseen herramientas administrativas y técnicas que les permitan tener una toma de decisiones asertiva y acorde a un mundo globalizado y consumista. Se aprecia, por parte de los empresarios, un desconocimiento del impacto de la globalización y de la apertura de los mercados. Se tiene la idea de que siempre se debe hacer lo mismo para el mismo mercado meta con las mismas herramientas y los mismos procesos, no existe un pensamiento innovador.

Si las empresas nacionales carecen de ventajas competitivas sobre sus productos y servicios, no lograrán mantener una competitividad adecuada ante aquellas entidades internacionales que ingresan al país o que tienen representación por medio de las importaciones de bienes y servicios por parte de la población. Por estas características propias de un sector desprotegido y descuidado por el estado, se considera de suma importancia la realización de un estudio de sus capacidades administrativas y estratégicas.

La investigación tiene una alta relevancia a nivel cantonal, pues existen muchas micro, pequeñas y medianas empresas dedicadas al servicio turístico que representan un soporte al desarrollo social y económico del cantón. Es de interés local lograr potenciar el crecimiento de cada una de estas empresas para que se conviertan en fuerzas sólidas de la economía. El estudio tiene el objetivo trazado de analizar las carencias y necesidades administrativas y estratégicas presentes en estas organizaciones con poca capacidad de respuesta ante el impacto de la apertura comercial y demás aspectos propios de una alta globalización en el país.

\section{PLANTEAMIENTO DEL PROBLEMA}

El problema clave que se descifra ante la información analizada es determinar qué limitaciones y necesidades en capacidad de gestión administrativa y estratégica presentan las MIPYMES del sector turismo en Pérez Zeledón para lograr un desarrollo oportuno y competitivo en el actual mercado globalizado. Dar una respuesta satisfactoria al problema garantiza el beneficio del sector y a la economía de un cantón en desarrollo. Se asegura el aumento de la competitividad de la región en el sector turismo, en la generación de empleos de cali- 
dad, en la diversificación de ofertas de bienes y servicios, en el mejoramiento administrativo y en la adopción de estrategias acorde a los recursos existentes y a las oportunidades del mercado.

\section{OBJETIVOS}

\section{Objetivo general}

Analizar la gestión administrativa y estratégica de las MIPYMES del sector turismo, del cantón de Pérez Zeledón, ante un mercado globalizado.

\section{Objetivos específicos}

1. Realizar un diagnóstico sobre la gestión administrativa y estratégica llevada a cabo por las micro, pequeñas y medianas empresas turísticas de Pérez Zeledón.

2. Identificar las capacidades administrativas y estratégicas de las MIPYMES del sector turismo que impactan positiva o negativamente el funcionamiento y la competitividad de la organización.

3. Detectar las fortalezas y las debilidades de la gestión de las MIPYMES turísticas que marcan el éxito y posicionamiento en el mercado actual.

\section{CONTEXTO GEOGRÁFICO}

El estudio se encuentra delimitado al cantón de Pérez Zeledón, el número 19 de la provincia de San José, ubicado en la zona sur del país, donde forma parte de la llamada Región Brunca. Este territorio comprende una extensión aproximada de 9905.51 km2 y fue cimentado en el año 1931. Su área está compuesta por un total de once distritos: San Isidro del General, Rivas, General Viejo, Platanares, Daniel Flores, San Pedro, Pejibaye, Páramo, Cajón, Río Nuevo y Barú. Cada uno de estos sectores con sus propias características geográficas, sociales y económicas, donde se encuentran distribuidas las empresas analizadas.
Pérez Zeledón en una región rica en recursos naturales, de los cuales muchas personas han sabido captar las oportunidades ofrecidas y han incurrido en la formación de empresas que potencien el recurso existente. El Cerro Chirripó es el mayor atractivo natural de la zona, ya que atrae a miles de turistas nacionales y extranjeros, que se convierten en clientes y consumidores de los bienes y servicios producidos por la región. Pese a todo, aún se puede realizar un mayor aprovechamiento de los insumos que ofrece el área.

\section{CONTEXTO ORGANIZACIONAL}

Las organizaciones surgen por la unión de personas que persiguen un objetivo específico y que buscan la cooperación con el propósito de lograr disminuir las cargas individuales. "Una organización existe sólo cuando: 1. Hay personas capaces de comunicarse, 2. Dispuestas a contribuir en una acción conjunta, 3. A fin de alcanzar un objetivo común" (Chiavenato, 2011, p. 6). Como lo indican Robbins y Coulter (2011), la organización "es un acuerdo deliberado de personas para llevar a cabo un propósito específico" (p.14).

Para efectos de la investigación, es importante señalar cómo se clasifican (en micro, pequeña y mediana empresa) las organizaciones, según su tamaño. El MEIC (2012) establece la siguiente fórmula para determinar la clasificación:

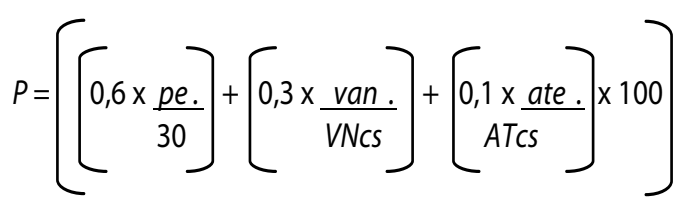

Donde:

P: Puntaje obtenido por la empresa.

pe: Personal promedio empleado por la empresa durante el último período fiscal. 
NTcs: Parámetro de referencia para el número de trabajadores de los sectores de comercio y servicios.

van: Valor de las ventas anuales netas de la empresa en el último período fiscal.

VNcs: Parámetro monetario de referencia para las Ventas Netas de los sectores De comercio y servicios.

ate: Valor de los activos totales netos de la empresa en el último período fiscal.

ATcs: Parámetro monetario de referencia para los Activos Netos de los sectores de comercio y servicios.

Se clasifica según el puntaje "P" obtenido, según el siguiente criterio:

- Microempresa: $P \leq 10$

- Pequeña Empresa: $10<P \leq 35$

- Mediana Empresa: $35<P \leq 100$

Otra manera de saber la clasificación es la utilizada por la Caja Costarricense de Seguro Social (CCSS), donde las empresas se clasifican según la cantidad de empleados por entidad. Así, se denomina microempresa cuando posee hasta 5 empleados; pequeña empresa, entre 6 y 30 empleados; mediana empresa, entre 31 y 100 empleados y más de 100 trabajadores se considera grande. Para fines de este trabajo, se tomada la clasificación según la CCSS.

Las MIPYMET son empresas que se basan en la estrategia turística nacional, según el Plan de desarrollo turístico sostenible del ICT. Esta estrategia está enfocada en un turismo de naturaleza con el objetivo de mantener la diferenciación como destino turístico. El Plan involucra estrategias para el desarrollo y el crecimiento, identificadas principalmente en mejorar la oferta de servicios, potenciar el uso de los recursos, mejorar la calidad de los servicios y mejorar las capacidades adquiridas. (ICT, 2011).

Las empresas, en la realización de la gestión administrativa y estratégica, deben establecer claramente una misión y visión que proporcione el camino a seguir. "Una declaración clara de la misión describe los valores y las prioridades de la organización, la declaración de la visión, a menudo se considera como el primer paso a la planeación estratégica" (Fred, 2008, p. 11). De igual manera, "la visión organizacional, o visión del negocio, se refiere a lo que la organización desea ser en el futuro" (Chiavenato, 2011, p. 18).

Al analizar la forma en que se organizan las MIPYMET en Pérez Zeledón, se determinó que las principales actividades en que se basa su oferta son: hospedajes, servicios gastronómicos, servicio de transporte turístico, agencias de viajes, caminatas, visita a destinos específicos, pesca deportiva, entre otros.

Al estudiar el aspecto organizacional del sector, se detalla que estas entidades cuentan con recurso humano limitado en capacidades técnicas, administrativas y estratégicas que exige un mercado altamente competitivo. Al contar con poco recurso financiero se limita la inversión en capacitación y entrenamiento de los empleados. La falta de capacidades empobrece a la organización y podría imposibilitar el correcto desarrollo de las empresas.

Brenes (2008), en su trabajo sobre micro y pequeña empresa turística, señala que:

Por su origen, la mayoría de MYPET son empresas de familia. Por ejemplo, la familia posee una propiedad ubicada en un lugar con potencial turístico y decide emprender. Para hacerlo, convierte la propiedad en albergue, desarrolla cambios como senderos y espacios para ofrecer excursiones. Otro ejemplo 
lo constituyen las agencias de viajes cuyos propietarios son profesionales del turismo que incorporan familiares en sus empresas (pp.19-20).

\section{MARCO TEÓRICO}

El objetivo principal del presente apartado es cimentar teóricamente la realización de la investigación, la importancia de los temas abordados y conceptos actuales que se relacionan con el problema analizado.

\section{GESTIÓN ADMINISTRATIVA}

El entorno globalizado se caracteriza por brindar información variada proveniente de cualquier parte del mundo. Este ataque de conocimiento provoca alteraciones en el diario funcionar de las empresas, cambiando de forma importante la manera de hacer el trabajo. Ante este panorama, la única forma de prevenir su impacto es crear un pensamiento proactivo dentro de la organización.

El posicionamiento correcto en el mercado nacional y el logro de un adecuado desarrollo empresarial están estrechamente relacionados con el grado de eficiencia y eficacia operacional de las entidades. La gestión administrativa involucra todos los aspectos dinamizadores de la organización; significa realizar una adecuada administración. La administración, según Robbins y Coulter (2011) "involucra la coordinación y supervisión de las actividades de otros, de tal forma que estas se lleven a cabo de forma eficiente y eficaz" (p. 6).

Por medio de la administración se logra integrar todas las actividades individuales de la organización de manera que se unifique el accionar y se alcance la calidad operativa y el desarrollo empresarial y económico. En resumen "es darle sentido a las diversas situaciones que enfrentan las organizaciones, tomar decisiones y formular planes de acción para resolver problemas de la organización" (Laudon y Laudon, 2008, p. 18).

Las entidades deben procurar desarrollar e implementar una visión de mejoramiento continuo de los procesos. Esta visión se logra mediante una cultura organizacional, la cual "se ha descrito como los valores, principios, tradiciones y formas de hacer las cosas que influyen en la forma en que actúan los miembros de la organización" (Robbins y Coulter, 2011, p. 48).

Una entidad logra eficiencia al realizar su gestión operativa de forma tal que se ahorren al máximo los recursos e insumos empleados, sin incurrir en desperdicios o despilfarros innecesarios. De igual manera, alcanzará la eficacia al tener una correcta toma de decisiones, donde se garantice que las actividades, procesos y estrategias seguidas son las mejores y se logren las metas y objetivos trazados.

El papel de los dirigentes es preponderante en el buen caminar de la compañía. Por ello, el desarrollo de su talento humano es necesario. Como acertadamente lo dice Fred "Ios objetivos, las estrategias y las políticas tienen pocas oportunidades de triunfar si los gerentes y empleados no son dirigidos para implementar las estrategias una vez que se han formulado" (Fred, 2008, p. 134).

La gestión administrativa integra la ejecución de un sinnúmero de tareas y funciones. Según Robbins, "éstas se han resumido en cuatro: planeación, organización, dirección y control" (Robbins y Coulter, 2011, p.8). En forma concreta, se puede inferir que la planeación es la definición de objetivos, metas, políticas, normas, procesos y todas las actividades en general; es decir, representa el plan de trabajo.

Para una MIPYMET es primordial obtener o crear una ventaja competitiva sobre sus similares que le permita una diferenciación de sus competidores y un atractivo efectivo de sus 
clientes o consumidores. Esta ventaja "proviene de las habilidades clave de la organización, debido a que la organización hace algo que otros no hacen, o lo hace mejor que los otros" (Robbins y Coulter, 2011, p. 183).

El fin es establecer un proceso de negocio que responda al entorno y se ajuste a las necesidades de los consumidores. "Los procesos de negocios se refieren al conjunto de tareas y comportamientos relacionados que las organizaciones desarrollan a través del tiempo para producir resultados de negocios específicos y a la manera particular en la cual se organizan y coordinan estas actividades" (Laudon y Laudon, 2008, p. 7).

\section{GESTIÓN ESTRATÉGICA}

La planificación tiene el objetivo de darle vida al actuar de la organización, aclarando su razón de ser, el rumbo a seguir y las metas por lograr; en otras palabras, brinda la dirección u horizonte de la empresa. La planificación es dinámica y activa, pues se desarrolla y ejecuta en todos los procesos de la entidad durante toda su vida operacional.

Al hablar de estrategia se debe aclarar que esta enmarca el rumbo a seguir por la organización, de acuerdo a una planeación previa sobre sus oportunidades y amenazas. Fred (2008) indica que

Las estrategias son los medios por los cuales se logran los objetivos a largo plazo. Las estrategias empresariales incluyen la expansión geográfica, la diversificación, la adquisición, el desarrollo de productos, la penetración de mercado, la reducción de gastos, el retiro de inversiones, la liquidación y las empresas conjuntas (p. 13).

Según Brenes (2008), "la estrategia es un conjunto de decisiones y acciones que le dan identidad a la empresa y le permiten alcanzar sus objetivos" (p. 35). Las estrategias deben plasmar la visión y misión de la empresa, "son los planes respecto a la manera en que la organización hará cualquier cosa que sea necesario hacer en el negocio, cómo competir exitosamente, y cómo atraer y satisfacer a sus clientes con el objeto de lograr sus objetivos" (Robbins y Coulter, 2011, p. 176).

La gestión estratégica consiste en oficiar una integración coherente entre los sistemas de gestión de la organización, donde la más relevante es la administrativa, con la gestión de una estrategia clave y articulada cuyo objetivo global es lograr eficiencia y eficacia operativa. Fred concibe la administración estratégica como "el arte y la ciencia de formular, implementar y evaluar decisiones multifuncionales que le permitan a una organización lograr sus objetivos" (Fred, 2008, p. 5). Es por ello que la toma de decisiones toma mayor relevancia y se convierte en la labor de mayor responsabilidad para los dirigentes. "La toma de decisiones es un proceso, no es un simple acto de elegir entre alternativas" (Robbins y Coulter, 2011, p. 130).

\section{GLOBALIZACIÓN}

La globalización "es el proceso de mayor interdependencia entre los países y sus ciudadanos"; "Consiste en una mayor integración de mercados de productos y servicios entre las naciones por medio del comercio, migración e inversión extranjera; es decir por medio de los flujos internacionales de productos y servicios, de personas y de inversión, como en el caso de equipo, fábricas, acciones y bonos" (Carbaugh, 2009, p. 2).

Las organizaciones en el mundo actual deben tener la capacidad de transformar la información, las ideas, estrategias y los nuevos conceptos en innovaciones empresariales. El entorno globalizado es de continuo cambio, como bien lo indica Brenes (2008): "las empresas son similares a los seres vivos pues cambian conti- 
nuamente y están inmersos en comunidades también cambiantes" (p. 38). El cambio no es malo y las empresas deben responder a él, adaptarse y mejorar.

El entorno cambia con bastante rapidez, las necesidades de los consumidores se ajustan constantemente, la información varía en el mercado de acción, se da el nacimiento de nuevas técnicas y estrategias, todo por el impacto de la globalización. Estos aspectos constatan entonces que:

La idea de que el mundo es cada vez más pequeño es notoriamente cierta en el caso de las organizaciones actuales. Con los rápidos avances en la tecnología y las comunicaciones, el tiempo necesario para ejercer una influencia en todo el mundo, incluso en los lugares más remotos, se redujo de años a sólo segundos. Mercados, tecnologías y organizaciones están cada vez más conectadas entre sí (Daft, 2011, p. 7).

La innovación, valor fundamental para el desarrollo empresarial, es otro de los aspectos que han tomado su relevancia gracias a los efectos de la globalización. En términos sencillos, la empresa que logre la adaptabilidad al entorno, se ajuste al cambio constante, incorpore la mejora continua, tenga una adecuada transferencia de información interna y externa, tendrá la ventaja competitiva para posicionarse en lo alto del mercado.

La globalización, sus beneficios y perjuicios deben ser considerados como necesarios para el logro de la competitividad organizacional. Las empresas adoptarán aquellas prácticas que les proporcionen ventajas competitivas y se aseguraran de evitar el impacto negativo de información inservible y poco productiva para la entidad. El entorno es así, nada ni nadie puede cambiar la forma en que actualmente influye la información, tecnologías, prácticas, estrategias e innovaciones en la manera en que se desarrollan las empresas.

\section{CAPACIDADES ADMINISTRATIVAS Y ESTRATÉGICAS}

El grado de competitividad de una empresa depende mayormente de las capacidades administrativas y estratégicas con que se cuentan para actuar. Las empresas deben tener un enfoque de aumento eficiente y permanente de sus capacidades. Existe un sinnúmero de capacidades que las empresas deben lograr pero, sin lugar a dudas, la capacidad de gestión administrativa y estratégica, detallada en puntos anteriores, es la más primordial.

La micro, pequeña y mediana empresa turística debe establecer mecanismos que aseguren que se dé un aprendizaje continuo dentro de la empresa, pues "el crecimiento continuo de una PYME requiere la gestión y el desarrollo de diferentes competencias y capacidades, y de esta forma, el punto de vista interno de la empresa analiza el alineamiento de las estrategias de negocios con los recursos de la empresa" (Reina y Ocampo, 2011, p. 35).

La buena administración se centra en la eficiencia y eficacia operativa; por ello, la capacidad de trabajar obteniendo los mejores resultados mediante la utilización de pocos recursos se debe convertir en una regla a seguir. La racionalización de todos los recursos existentes en la compañía proporciona una ventaja competitiva sobre sus similares.

Como se ha mencionado, el capital humano es significativo para las organizaciones. Actualmente, el interés se centra en dotar a este recurso de talento.

La base de la Gestión está en las habilidades, talentos y aptitudes del liderazgo y su gente, que día a día amalgamados como un todo, trabajan en pro de cristalizar la Planificación Estratégica 
y así, se van desarrollando las habilidades organizaciones que le dan sentido, color y textura a la gestión (Tarantino, 2012, párr. 5).

Solo con la ayuda de un personal capacitado, la organización logrará desarrollar ventajas sobre sus competidores. Esta ventaja "se refiere a lo que distingue a la organización y le proporciona una ventaja distintiva para cumplir las necesidades del cliente en el mercado. La estrategia cambia necesariamente con el tiempo para ajustarse a las condiciones del entorno (...)" (Daft, 2011, p. 61). Uno de los desafíos para las organizaciones, según Daft (2011), "es responder con rapidez y decisión a los cambios en el entorno, las crisis organizacionales o las expectativas de los clientes" (p. 9).

Las organizaciones y su personal deben convertirse en proactivas, para desarrollar competencias laborales; estas son fundamentales para el logro de objetivos institucionales. Los conocimientos adquiridos y ampliados se transforman en habilidades y destrezas necesarias para un buen desempeño en el trabajo y brindan a la empresa herramientas para superar obstáculos en el camino (Flores, 2013, p. 4).

Para el desarrollo de capacidades administrativas y estratégicas, las organizaciones deben implementar programas de capacitación, adiestramiento y formación del personal. Únicamente por medio de la capacitación preventiva se asegurará dotar al personal de herramientas para la correcta toma de decisiones. Este empoderamiento debe llegar a todos los niveles dentro de la organización.

\section{FORTALEZAS Y DEBILIDADES}

En todo momento se deben tener claras las fortalezas y las debilidades de la empresa para que los esfuerzos vayan dirigidos a eliminar aquellas deficiencias al interno de la entidad y, al mismo tiempo, transformar las fortalezas en ventajas comparativas sobre los competidores. "Las fortalezas y debilidades se determinan en relación con los competidores. La deficiencia o superioridad relativa es una información importante. Identificar y evaluar las fortalezas y debilidades de la organización en las áreas funcionales de una empresa son actividades esenciales de la administración estratégica" (Fred, 2008, p. 12).

Las fortalezas, debilidades, oportunidades y amenazas deben ser consideradas en todos los procesos activos de la organización, desde las etapas previas de la planeación hasta la implementación de procesos y negocios. Las gestiones administrativa y estratégica no tendrían éxito si estos aspectos internos y externos de la organización no son tomados en sus procesos.

\section{DESARROLLO EMPRESARIAL}

El principal fin de las organizaciones es el logro del desarrollo empresarial, visto a través de un alto grado de eficiencia y competitividad en el mercado. Para alcanzar este objetivo, debe existir una mentalidad innovadora, donde se potencialice el aprovechamiento de las oportunidades que ofrece el entorno.

Al hablar de un desarrollo empresarial, se espera la adopción de conductas y procesos mejorados y nuevos. "Algunos cambios ocurren debido a las oportunidades que surgen, mientras que otros se planean. El término desarrollo se aplica cuando el cambio es intencional y se planea con anticipación" (Chiavenato, 2011, p. 348). Las empresas deben gestionar el cambio para así lograr el desarrollo anhelado.

El desarrollo empresarial se adquiere teniendo un control oportuno del entorno y sus repercusiones en los procesos internos de trabajo. La empresa debe ejecutar una evaluación de todos los procesos en busca de las fortalezas y debilidades que le atañen. El desarrollo depende de la capacidad en identificar, potenciar 
y crear las fortalezas, además de identificar sus debilidades e implementar correcciones y mejoras sustanciales.

La convicción de ir siempre hacia adelante será el origen de una cultura de mejoramiento y calidad. Según un artículo, los gerentes tienen entre sus responsabilidades el asumir el reto de llevar a la organización hacia la excelencia y la competitividad mediante la implantación de modelos capaces de transformar la cultura organizacional (Vecino, 2011).

\section{METODOLOGÍA}

La importancia de describir el tipo de investigación establecida radica en visualizar de antemano los posibles alcances y resultados esperados de acuerdo con las particularidades propias de cada tipo existente. Se determina el tipo de investigación, los instrumentos de recolección de información, la forma de obtenerla y las diferentes fuentes que serán abarcadas y consultadas por el estudio. Se suministra el detalle metodológico desarrollado de acuerdo con los objetivos generales y específicos determinados y se puntualizan las variables analizadas, preponderantes en la investigación.

La investigación ha sido ejecutada bajo un enfoque cuantitativo, lo que define un procedimiento secuencial de las etapas trazadas por el estudio. Este tipo de investigación es el más utilizado por su adaptabilidad a la medición de fenómenos sociales y económicos y su objetividad en el logro de los resultados. Se utilizó esta perspectiva investigativa con el fin de obtener una medición eficiente de las variables identificadas de acuerdo a los objetivos específicos.

La visión cuantitativa permite, por medio de todo un proceso formal, explicar las causas de un determinado problema, estableciendo para esto nuevos conocimientos e ideas a partir de documentos e investigaciones previas. Tiene una base sólida que la faculta para que los resultados obtenidos por medio de su aplicación sean útiles para terceros y que dichos resultados lleguen a ser representativos de una población o sector determinado.

Toda la investigación sigue un proceso estructuralmente claro y guiado desde el inicio de la presencia de un conflicto o problema, hasta los procedimientos de recopilación de información y la interpretación final de los datos. Es importante mencionar que se traza un proceso estadístico para la interpretación de la información y la manera de presentarla al lector. Los datos estadísticos son relevantes para acertar o refutar ideas y teorías.

Como lo indica Barrantes (2010), el método cuantitativo "(...) se desarrolla más directamente en la tarea de verificar y comprobar teorías por medio de estudios muestrales representativos. Aplica los test y medidas objetivas, utilizando instrumentos sometidos a pruebas de validación y confiabilidad" (p. 70). Este tipo de análisis cuenta con una serie de instrumentos de recolección de información propios del enfoque, pues deben responder a las exigencias que plantea el propio modelo. "Esta recolección se lleva a cabo al utilizar procedimientos estandarizados y aceptados por una comunidad científica. Para que una investigación sea creíble y aceptada por otros investigadores, debe demostrarse que se siguieron tales procedimientos" (Hernández, Fernández y Baptista, 2010, p. 5).

Al realizar investigaciones cuantitativas, como su nombre lo indica, es fundamental contar con la mayor cantidad de información posible. Por ello, la muestra seleccionada debe ser lo más representativa que se pueda. De la misma manera, los procesos utilizados deben ser ca- 
paces de brindar confiabilidad al estudio y validez para cualquier ente que la desee emplear.

El modelo cuantitativo se ajusta a las necesidades de la investigación aquí planteada, pues responde al requerimiento de generar un conocimiento generalizado de la gestión administrativa y estratégica de la micro, pequeña y mediana empresa turística del cantón de Pérez Zeledón. Además, permite generar datos estadísticos acerca de los aspectos que ocasionan un reducido crecimiento empresarial y económico del sector.

Dentro del método cuantitativo se encuentra el estudio descriptivo, el cual se ajusta a las pretensiones de la investigación desarrollada, ya que con los resultados obtenidos se describen las características, necesidades y particularidades presentes en las micro, pequeñas y medianas empresas del sector turismo. El objetivo central de la investigación descriptiva es: "la descripción de fenómenos. Se sitúa en un primer nivel del conocimiento científico. Usa la observación, estudios correlaciónales y de desarrollo" (Barrantes, 2010, p. 64).

Se indica entonces que "los estudios descriptivos buscan especificar las propiedades, las características y los perfiles de personas, grupos, comunidades, procesos, objetos o cualquier otro fenómeno que se someta a un análisis" (Hernández et al., 2010, p. 80). De la misma manera, Hernández et al. (2010) mencionan que "Ios estudios descriptivos son útiles para mostrar con precisión los ángulos o dimensiones de un fenómeno, suceso, comunidad contexto o situación" (p. 80).

La investigación alcanzó un alto grado de profundidad explicativa acerca de la realidad del sector económico de las MIPYMET, lo que origina pasar de una etapa descriptiva a una explicativa. Los estudios explicativos llegan a "responder por las causas de los eventos y fenómenos físicos o sociales. (...) su interés se centra en explicar por qué ocurre un fenómeno y en qué condiciones se manifiesta, o por qué se relacionan dos o más variables" (Hernández et al. 2010, p. 84).

Este tipo de investigación fue implementada con el propósito cabal de recopilar, analizar, describir y explicar la gestión administrativa y estratégica regida en las micro, pequeñas y medianas empresas dedicadas a servicios turísticos en la zona de Pérez Zeledón. El tipo de estudio cuenta con todos los beneficios requeridos y enriquece el logro de los objetivos y la calidad del trabajo.

El estudio planteó la necesidad de obtención de información relevante de diferentes fuentes primarias y secundarias, las cuales debieron ser analizadas para la generación de resultados. Se consultaron fuentes de información clasificadas en secundarias y primarias, de acuerdo con sus alcances. Estas se explican a continuación.

Se consideran recopilaciones de datos anteriores realizados por autores corporativos y profesionales que estén relacionados con el tema desarrollado. Se incluyen documentos y compilaciones realizadas por organizaciones que han abordado el papel de las micro, pequeñas y medianas empresas en Costa Rica.

Se toman en cuenta fuentes de registros de organizaciones: normas, manuales, políticas, estrategias, planes de negocios, documentos de fuentes electrónicas, libros y material didáctico disponible y revistas. Las fuentes primarias son consideradas como información de primera mano, las cuales generan datos acerca del problema abarcado por la investigación. Para tales efectos, es considerada toda fuente primaria de información concerniente al papel actual de las micro, pequeñas y medianas empresas que ofrecen servicios turísticos en Pérez Zeledón. Otras fuentes primarias de información son los empleados de las empresas seleccionadas para la inves- 
tigación, el papel del coordinador de la oficina regional del MEIC, el director ejecutivo de la Cámara de Comercio, Turismo, Industria y Agricultura (CCTIA).

\section{INSTRUMENTOS Y TÉCNICAS DE RECOLECCIÓN DE DATOS}

La herramienta de la observación directa es ideal para el análisis de fenómenos sociales y económicos. Es idónea para la obtención de datos, para brindar un diagnóstico sobre la gestión administrativa y estratégica de las organizaciones. El método de la observación tiene los beneficios de generar nuevos conocimientos y teorías originadas del estudio del comportamiento de un objeto determinado. "La observación es el procedimiento para obtener datos de la realidad mediante la percepción intencionada y selectiva de un objeto o fenómeno determinado" (Ulate y Vargas, 2012, p. 63).

Otra de las herramientas utilizadas en esta etapa fue la encuesta; dentro de esta técnica se encuentran instrumentos como los cuestionarios y las entrevistas estructuradas. "La encuesta es la técnica utilizada para conocer la opinión de la gente sobre una situación o un problema en el cual está involucrada" (Ulate y Vargas, 2012, p. 66).

Las entrevistas son constantemente empleadas por su alto grado de aceptación y funcionalidad para el investigador. En este caso, se optó por realizar entrevistas de forma personal y directa. La entrevista "es una conversación, generalmente oral, entre dos personas, de los cuales uno es el entrevistador y el otro el entrevistado." (Barrantes, 2010, p. 194).

Ahora bien, cada instrumento responde a un requerimiento de información. Con el fin de desarrollar la técnica de la observación directa, se dispuso contar en todo momento con un blog de notas que cumplió con el cometido de brindar la posibilidad de anotar toda aque-
Ila información indispensable en la explicación de comportamientos y fenómenos dentro del proceso de análisis. Al momento de realizar las visitas a las empresas determinadas, se realizaron anotaciones del entorno de la organización y de todo detalle pertinente para el estudio. Se utilizó la cámara fotográfica con el fin de evidenciar algunas de las empresas analizadas en la investigación, así como los principales servicios que ofrecen mostrando los tipos de actividades desarrolladas por las empresas.

Durante el desarrollo de la recopilación de información, se ejecutaron tres cuestionarios; dos de ellos aplicados por medio de la técnica de entrevista estructurada y el tercero de forma personal, donde el individuo contestaba directamente en el instrumento suministrado.

Según Gómez, citado por Barrantes (2010), "las funciones básicas del cuestionario son: obtener por medio de la formulación de preguntas adecuadas, las respuestas que suministren los datos necesarios para cumplir con los objetivos de la investigación" (p. 188). Con el fin de recabar información de los empleados de las MIPYMET sobre temas de interés para el estudio, se resolvió implementar un cuestionario dirigido a este sector de las entidades.

La muestra determinada es de tipo probabilístico, donde todas las empresas tienen la misma oportunidad de ser seleccionadas para el estudio. La selección de las empresas que forman parte de la muestra se realizó al azar con la aplicación del programa STATS. El tamaño de la población ( $N$ ), se estableció, mediante el uso de datos suministrados por el Instituto Nacional de Estadística y Censos; por medio de su oficina de información se solicitó vía correo electrónico la cantidad de empresas instauradas en Pérez Zeledón empresas dedicadas a hoteles, restaurantes y otras actividades de servicio. 
Para obtener el tamaño de la muestra se utiliza la fórmula y la aplicación STATS. Para calcular la muestra, se considera la Fórmula 1, se tomó

$$
n=\frac{N * Z^{2 *} p^{*} q}{e^{2 *}(N-1)+Z^{2 *} p^{*} q} \quad \text { Formula } 1
$$

un 95\% como nivel deseado de confianza para el muestreo y se selecciona un error estándar estimado de 5\%. Como se desconoce el porcentaje estimado de la muestra $(p)$, se toma como un $50 \%$, ya que este porcentaje permite obtener una muestra representativa, pues se define que la certeza total es igual a 1.

Donde:

$$
\begin{aligned}
& \mathrm{N}=\text { tamaño de la población }=102 . \\
& \mathrm{n}=\text { tamaño muestra } \\
& \mathrm{Z}^{2}=\text { con un nivel de confianza de } 95 \%=1.96 \\
& \text { al cuadrado }=3.8416 \\
& \mathrm{p}=\text { porcentaje estimado }=0.5
\end{aligned}
$$

$$
\begin{aligned}
& \mathrm{n}=\frac{102^{*} 3.8416^{*} 0.5^{*} 0.5}{0.0025^{*} 101+3.8416^{*} 0.5^{*} 0.5} \\
& \mathrm{n}=97.96 / 1.2129 \mathrm{n}=80 \cdot 76 \quad \mathrm{n}=81 \\
& \mathrm{q}=(1-\mathrm{p})=0.5 \\
& \mathrm{e}^{2}=\text { error estándar al cuadrado }=(0.05) 2= \\
& 0.0025 .
\end{aligned}
$$

Sustituyendo los datos en la fórmula y realizando los cálculos necesarios se obtiene una muestra de $n=81$.

Se obtuvo una muestra de 81 empresas de la población. Esta es representativa de la población, por la homogeneidad de las empresas del can- tón. Además, responde a que las empresas tengan una orientación hacia el turismo.

Como unidad de muestreo se toman todos aquellos responsables directos de la gestión administrativa y estratégica de las micro, pequeñas y medianas empresas turísticas que forman parte de la muestra de estudio. Se designa como responsable directo, ya que los individuos a cargo de las MIPYMET pueden ocupar puestos con diferentes designaciones. La unidad de muestreo es la misma unidad informante. Las otras unidades tomadas son los empleados de las empresas, el Ing. Jonathan Sequeira Ureña coordinador regional del Ministerio de Economía, Industria y Comercio y al director ejecutivo de la CCTIA.

\section{VARIABLES}

Las variables definidas para este estudio se describen a continuación.

Gestión administrativa: conjunto de actividades de planeación, organización, dirección, administración, coordinación y control sobre una determinada empresa.

Gestión estratégica: conjunto de acciones proactivas que aseguren el logro de un objetivo a mediano y largo plazo.

Capacidades administrativas y estratégicas: acumulado de habilidades idóneas y eficientes para el buen desarrollo de la gestión estratégica y administrativa de una organización.

Fortalezas y debilidades: aspectos internos de una organización que son positivos (fortalezas) o negativos (debilidades), y se determinan midiendo el grado de eficiencia. 


\section{INDICADORES}

- $\quad$ Número de empresas con visión y misión claramente establecidas.

- Grado de eficiencia administrativa.

- $\quad$ Nivel de eficacia en la toma de decisiones.

- Empresas que realizan planificación estratégica.

- $\quad$ Efectividad de estrategias actuales.

- Grado de adaptabilidad al cambio.

- Cantidad y calidad de las fortalezas y debilidades existentes en las organizaciones. Grado de aprovechamiento de oportunidades del mercado.

- Grado de integración y cohesión organizacional.
- Mecanismos de creación de competencias.

Grado de capacitación de los dirigentes y del personal.

\section{RESULTADOS}

A continuación, se muestran los resultados de la investigación y se analizan los factores positivos y negativos del accionar de las empresas turísticas. La idea era determinar el papel de los dirigentes de las empresas y los aspectos clave en la ejecución de las funciones involucradas en la administración de los negocios. Se debe aclarar que al final se utiliza una muestra de 72 empresas ya que 9 de ellas se rehusaron a proporcionar la información o fue imposible lograr un espacio de reunión entre el responsable y el investigador.

La Figura 1 muestra la distribución de empresas según el distrito de ubicación. Proporciona infor-

\section{FIGURA 1 \\ DISTRIBUCION DE EMPRESAS SEGUN DISTRITO}

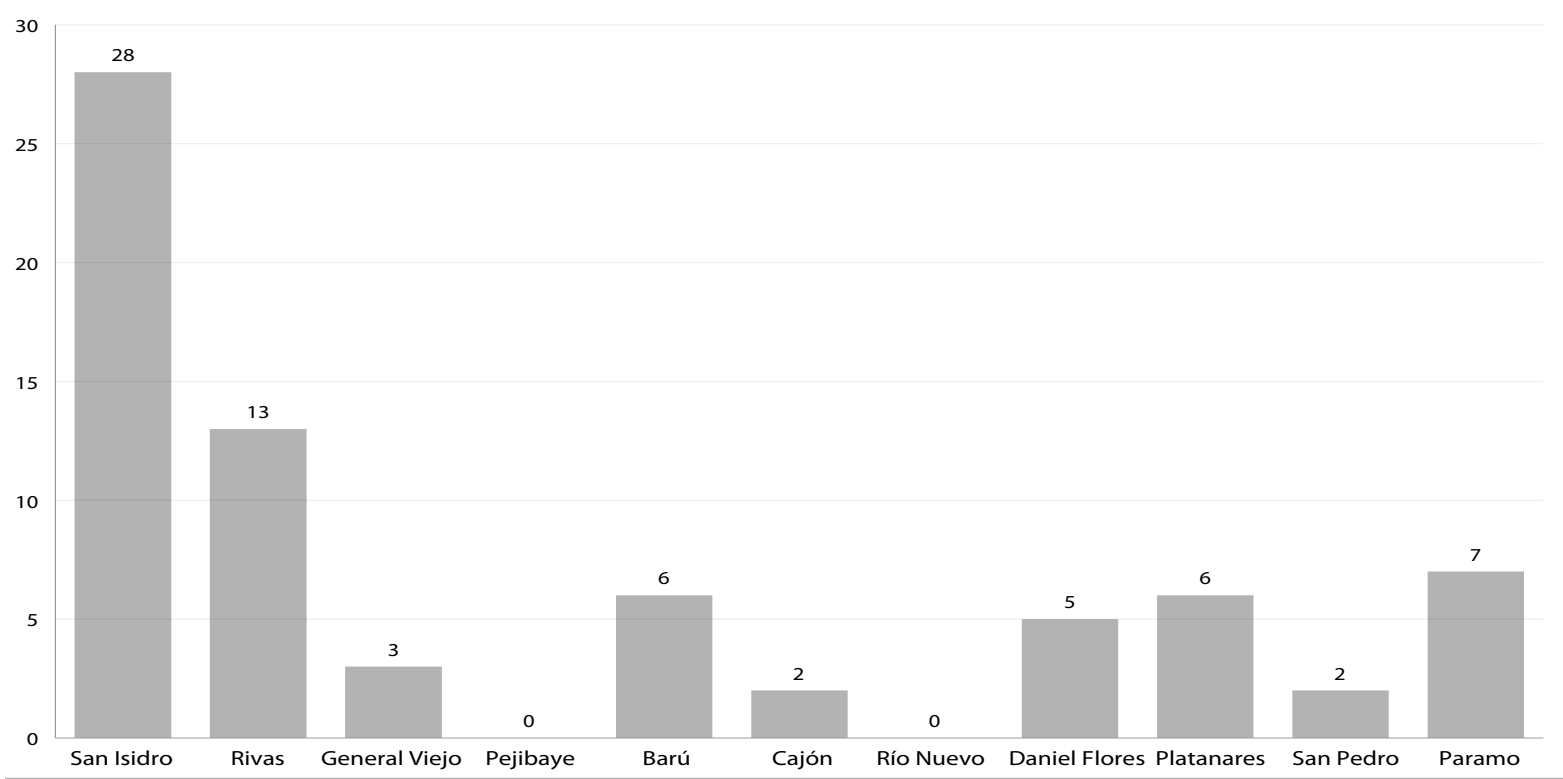

Fuente: Elaboración propia. 


\section{FIGURA 2 \\ DISTRIBUCION DE EMPRESAS SEGUN SU ACTIVIDAD}

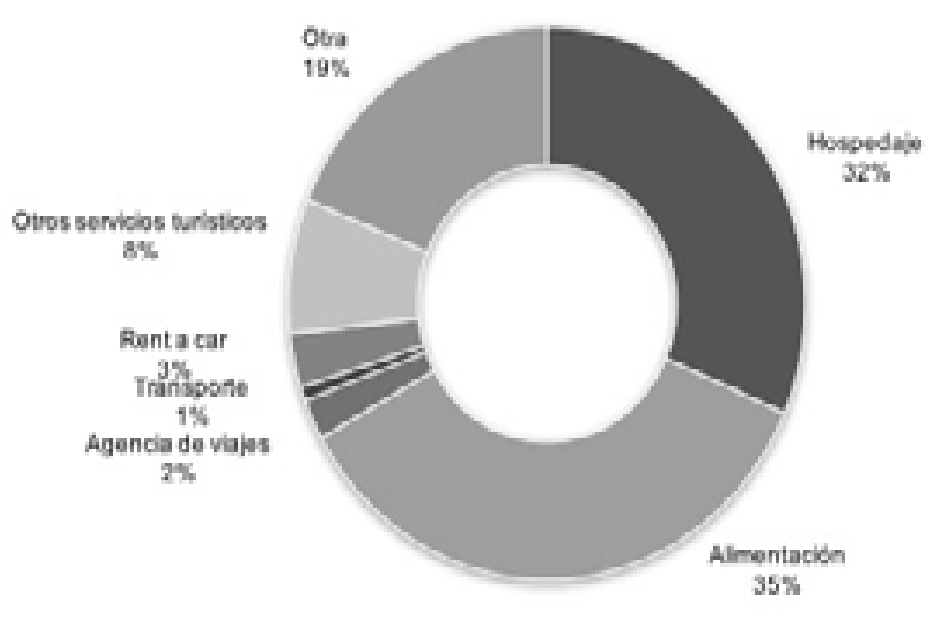

- Hospedaje = Almembiocion

- Agencia de viajes

- Transporte

- Rentacar

"Otros servicios turistices

. Otra

Fuente: Elaboración propia.

mación del alcance de la investigación al evidenciar que un $82 \%$ del territorio del cantón formó parte del estudio, dejando por fuera solamente dos (18\%) de los once distritos conformados en el territorio. De este $82 \%$ del territorio abarcado, los distritos que mayor cantidad de empresas provee son San Isidro, con un 39\%; Rivas, con 18\% y Páramo, con un 10\%. El 33\% restante está distribuido a lo largo del cantón.

En la Figura 2 se observa que las actividades de mayor oferta en el cantón de Pérez Zeledón son el Hospedaje y la alimentación, en un 67\% de las empresas. La competencia entre estas entidades es dura y se disputan un mercado local estrecho que demanda calidad y excelencia. El hospedaje es concebido desde todos sus ámbitos: hoteles, cabinas, cabañas, donde la variedad de la oferta sobresale.

El 74\% de las empresas bajo estudio cuentan con un personal no mayor a 5 empleados.
Este hecho se da debido a que la mayoría de entidades trabajan con recurso humano propio, por lo que miembros de la familia son los responsables de la ejecución de tareas administrativas y operativas. Estas microempresas gastan poco en contrataciones de personal. Hoteles medianamente estables ocupan el $25 \%$ de las compañías que cuentan con personal entre 6 y 30 . El Hotel del Sur es la organización que emplea a más de 31 trabajadores del cantón y se considera como un negocio de tamaño medio (ver Figura 3).

La Figura 4 constata que el $69.4 \%$ de las organizaciones tienen características familiares, naciendo con la idea de explotar un recurso o idea originada por el núcleo familiar. Estas entidades se caracterizan por su poca infraestructura, baja innovación, reducido talento humano, poco manejo de información y otros obstáculos que serán analizados más adelante. 
FIGURA 3

CLASIFICACIÓN DE EMPRESAS SEGUN SU NUMERO DE EMPLEADO

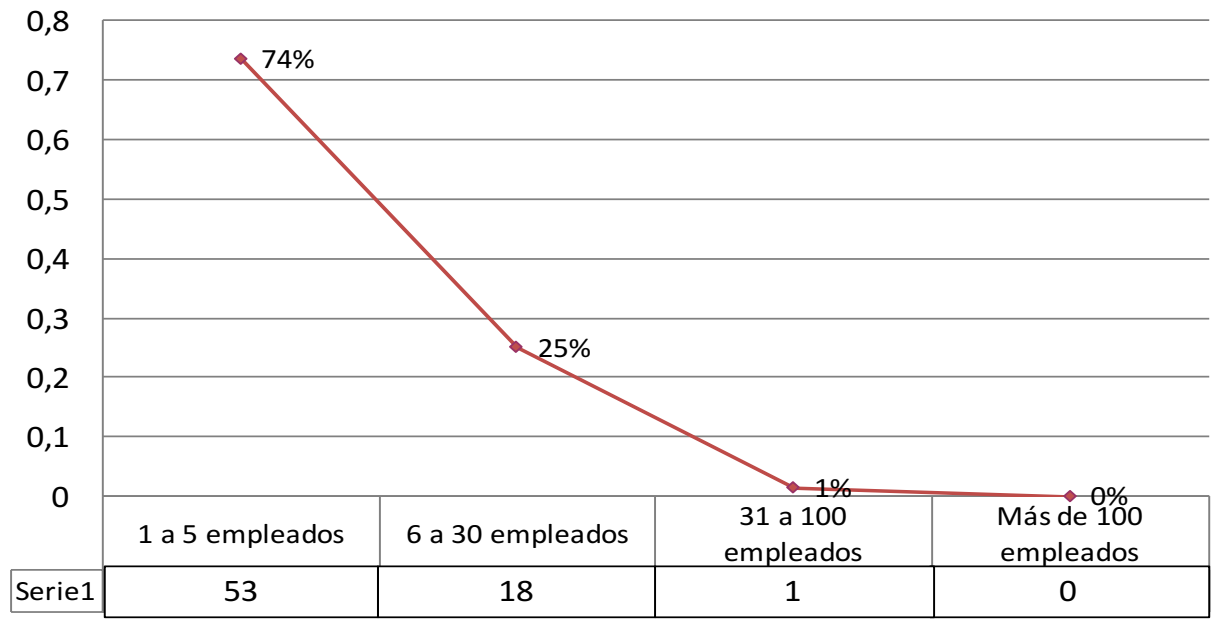

Fuente: Elaboración propia.

FIGURA 4

EMPRESAS SEGUN SU TIPO DE ORGANIZACION

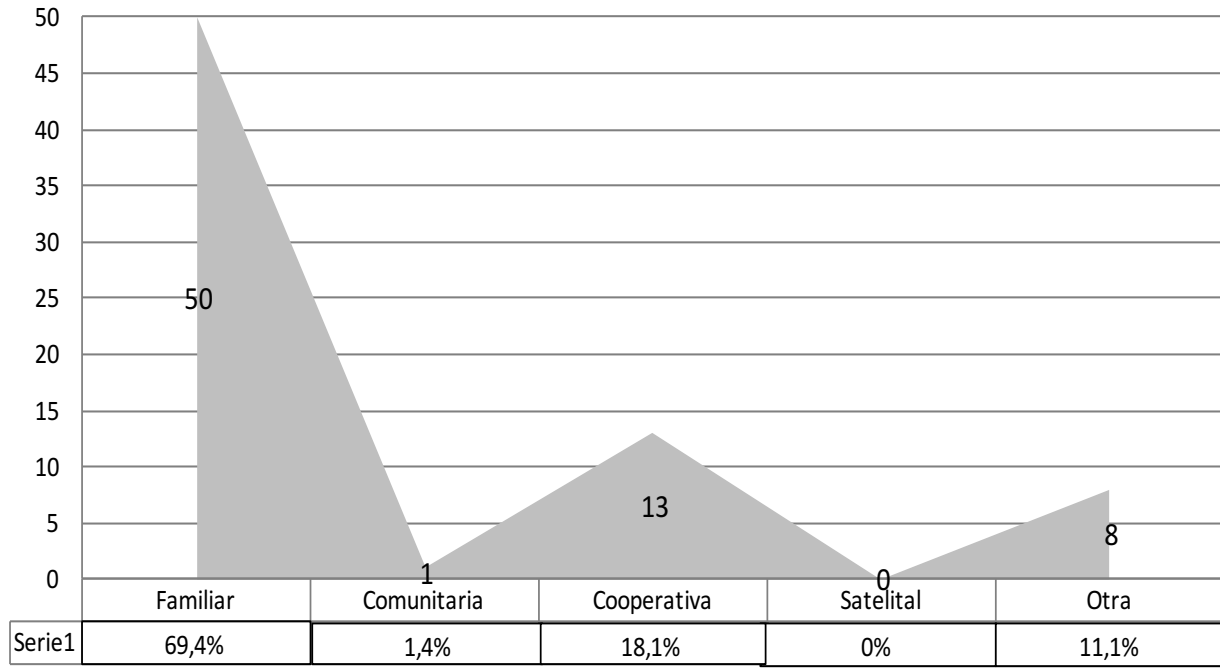

Fuente: Elaboración propia. 
El $11.1 \%$ de las empresas con otro tipo de organización son aquellas que expresan ser sociedades o que han surgido de la idea de un individuo que trabaja de forma independiente o trabaja para una firma extranjera. Se observa cómo un 0\% de las empresas son de carácter satelital (estas son las que se encuentran instauradas al interno de otra organización, pero no forman parte de ésta, sino que ocupan un espacio en ella y trabajan independiente). El hecho que existan pocas entidades comunitarias $1.4 \%$ y cooperativas $18.1 \%$ puede estar relacionado con el dato de poca formación de alianzas estratégicas.

En la Figura 5 se establece que un 63.9\% de las empresas analizadas cuenta de forma total o parcial con una visión de trabajo a nivel organizacional. Un 62.5\% de manera parcial o total dice trabajar bajo una misión clara y un 59.7\% trabaja con políticas, objetivos y normas instauradas de forma total o parcial dentro de la empresa. De manera importante, un 36.1\%, 37.5\% y $40.3 \%$ del total de empresas sus dirigentes expresa no trabajar con una visión, misión y objetivos definidos claramente.

La observación de campo sirvió también para corroborar que muy pocas de las empresas cuentan con manuales de puestos que permitan una orientación del empleado y el logro de un trabajo eficaz. Estos tres aspectos son pilares primarios de todo negocio en la actualidad globalizada, de ahí el grado de importancia que estas organizaciones logren planificar su misión, visión y objetivos con el fin de lograr competitividad, estabilidad y crecimiento. Para acompañar este dato, posteriormente se estudió si la formación empresarial y el nivel de escolaridad del dirigente como del empleado

FigURA 5

\section{EMPRESAS CON VISIÓN, MISIÓN Y POLÍTICA ORGANIZACIONAL}

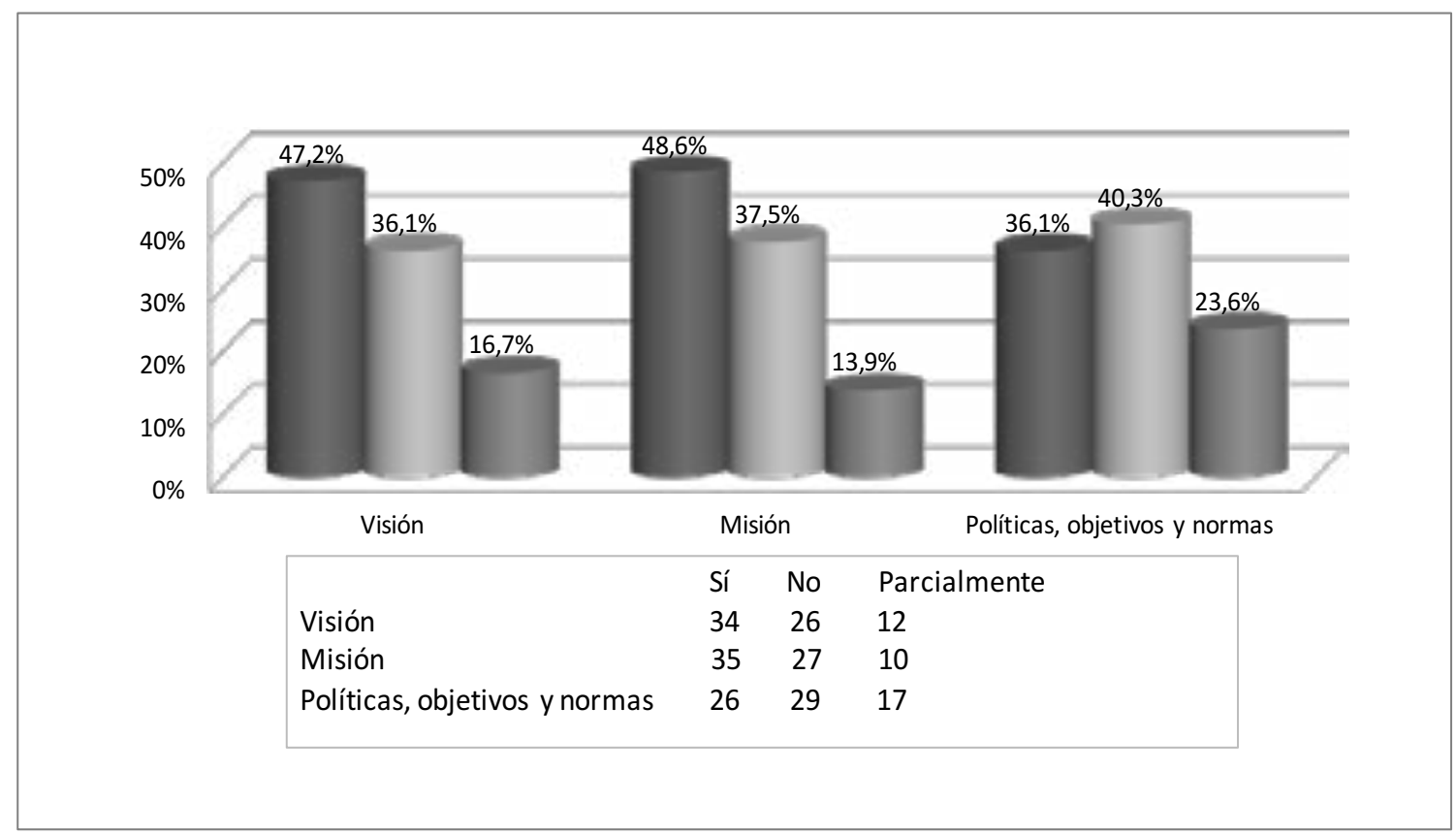

Fuente: Elaboración propia. 


\section{FUNCIONES ADMINISTRATIVAS REALIZADAS POR LAS MIPYMET}

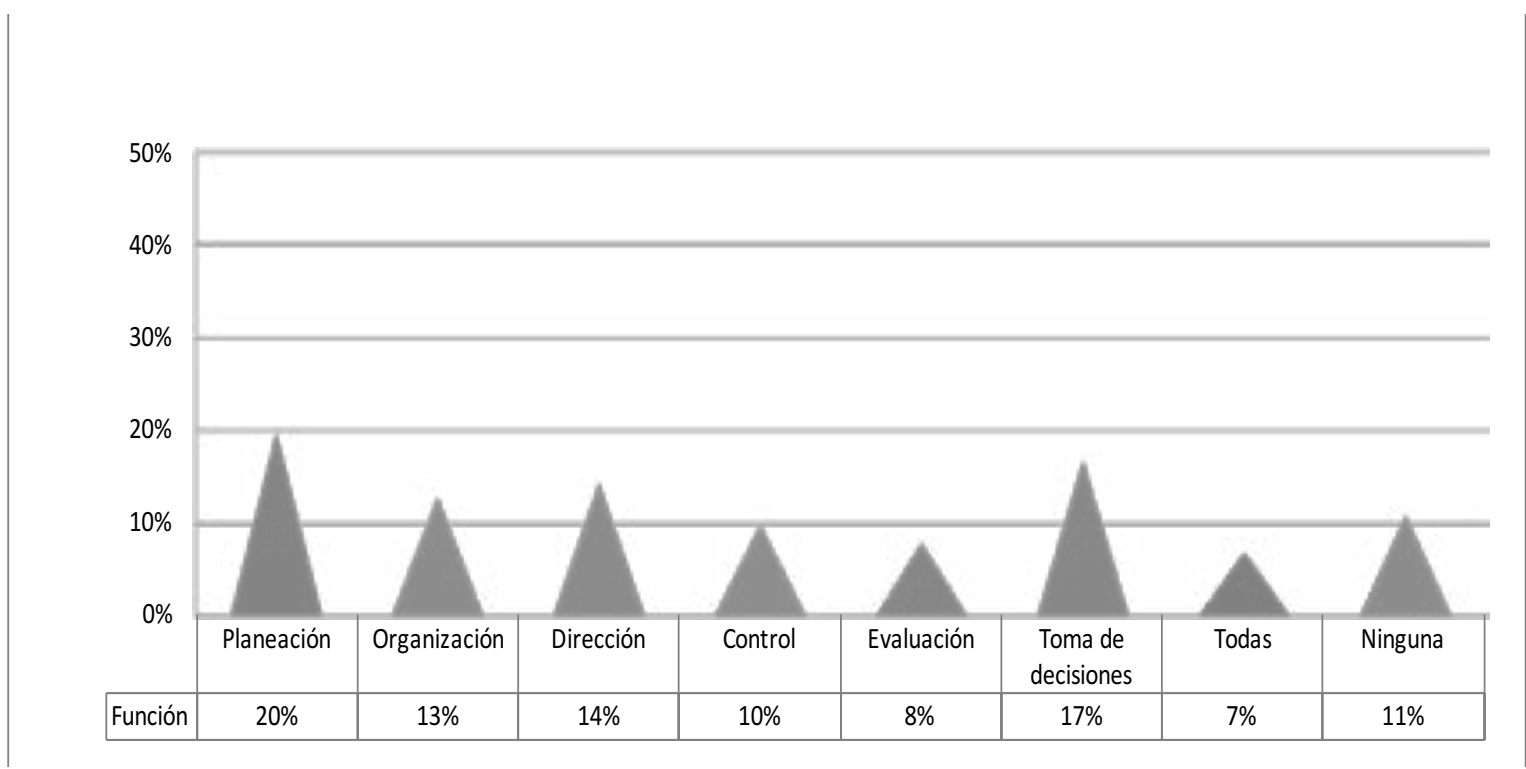

Fuente: Elaboración propia.

tienen efectos en la falta de estos lineamientos organizacionales.

La Figura 6, evidencia que únicamente un 7\% de todas las empresas involucradas detalla realizar todas las funciones descritas en el ítem consultado y las demás distribuyeron su respuesta en las diversas funciones. Además, un $11 \%$ de las respuestas reporta que no se realiza ninguna de las funciones de manera estructurada y estandarizada. Esto quiere decir que la mayoría de estas empresas trabaja sin planeación administrativa previa y únicamente toman decisiones a partir de información analizada o para resolver problemas que se presentan en la cotidianidad, sin establecer un procedimiento claro de gestión. Este fenómeno se demuestra más en las microempresas, ya que las empresas a mayor tamaña presentado, mayores funciones ejecutan. La evaluación, control, dirección y organización son las funciones que requieren mayor desarrollo dentro de las micro, pequeñas y medianas empresas analizadas.
El gerente ejecutivo de la Cámara de Comercio considera que estas empresas realizan las funciones definidas en el gráfico de una forma parcial. El coordinador del MEIC reafirma este criterio al opinar que la mayoría de MIPYMET no realiza estas funciones de forma eficiente y estructurada, por lo que no forman parte de la gestión que realizan.

La globalización y su impacto hacia el sector fueron considerados para la determinación de la gestión administrativa realizada. Un aspecto inherente para la investigación es la respuesta de las MIPYMET a los cambios de entorno y su adaptabilidad a dicha adecuación operacional. Por ello, como primer punto, se consultó sobre el nivel de mercado que es considerado para el desarrollo de la oferta brindada en el mercado.

Los valores relativos reflejados en el estudio establecen que solo el 30.6\% de las MIPYMET considera el mercado internacional para determinar su oferta. Esto puede transformarse 
en que dicho sector no da importancia a información internacional y no toma en cuenta estrategias, negocios, ideas, productos, servicios, culturas y otros que se generan a nivel global.

Tanto el coordinador de la oficina regional del Ministerio de Economía, Industria y Comercio, como el gerente de la cámara de Comercio, Industria, Turismo y Agricultura piensan que las MIPYMET no toman en cuenta el mercado global, y que basan su estrategia y gestión al mercado local y algunos pocos al regional.

Analizando la segunda variable del primer objetivo específico, se procedió a estudiar la gestión estratégica seguida por las micro, pequeñas y mediadas empresas turísticas de Pérez Zeledón. Por medio de la experiencia en sus puestos de trabajo se consulto a los dirigentes del MEIC y la Cámara de Comercio, sobre las gestiones estratégicas que realiza el sector empresarial turístico. Ante el panorama, ellos tie- nen el criterio que estas empresas realizan una planeación y planificación estratégica de forma parcial. Este aspecto repercute negativamente en los resultados obtenidos del negocio y en el logro de objetivos a corto y largo plazo.

En la Figura 7, se observa que más de un 70\% de las empresas o no realizan la gestión estratégica o lo hacen de forma parcial. Este dato es sumamente relevante, pues en el mercado competitivo y globalizado es vital para toda organización, independientemente de su tamaño, contar con una estrategia de negocio clara y consolidada con el fin de lograr sus objetivos a corta y mediano plazo. Se puede considerar este punto identificado como uno de los de mayor importancia para la investigación.

Un dato preocupante es que el 8\% de las empresas no expresó seguir ninguna estrategia para competir y hacer frente al mercado de clientes. El 2\% que señaló gestionar otra estra-

FIGURA 7

\section{EMPRESAS QUE REALIZAN PLANEACIÓN Y PLANIFICACIÓN ESTRATÉGICA}

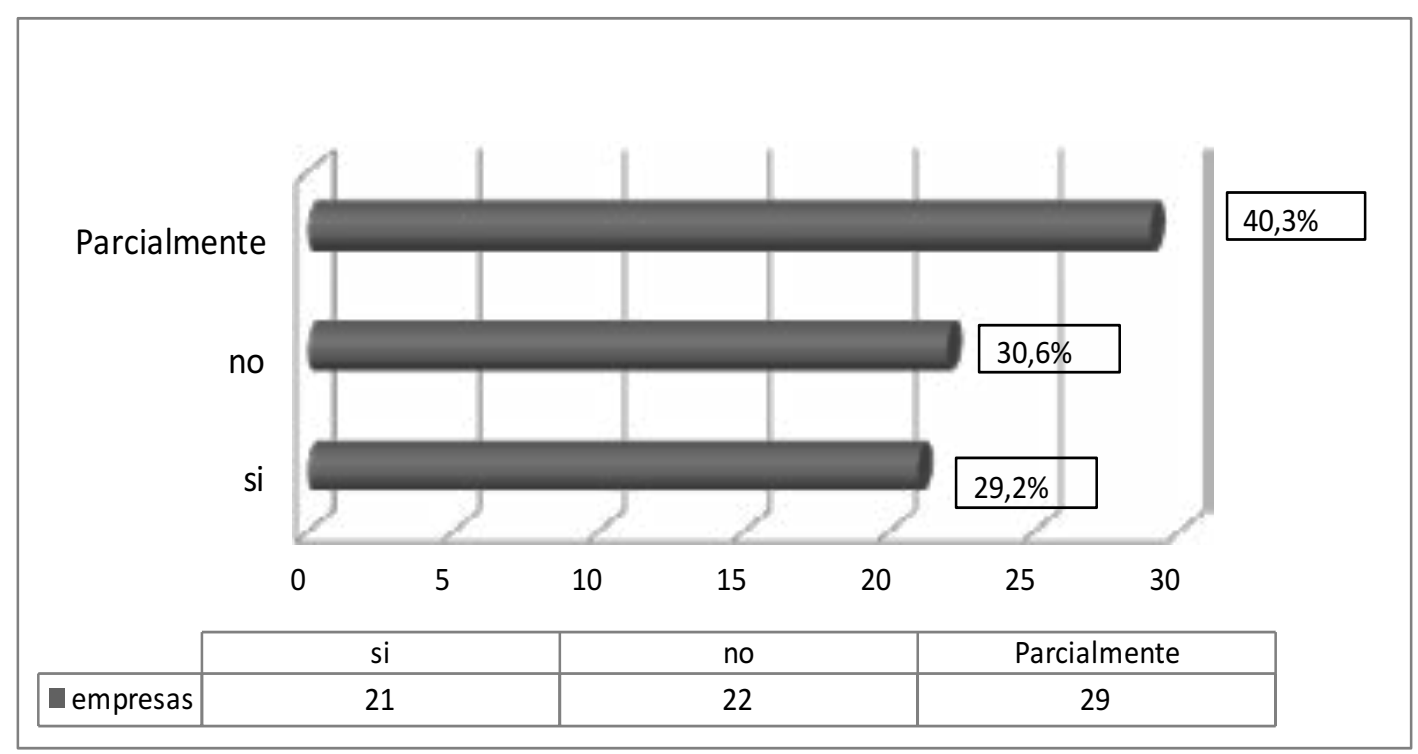

Fuente: Elaboración propia. 


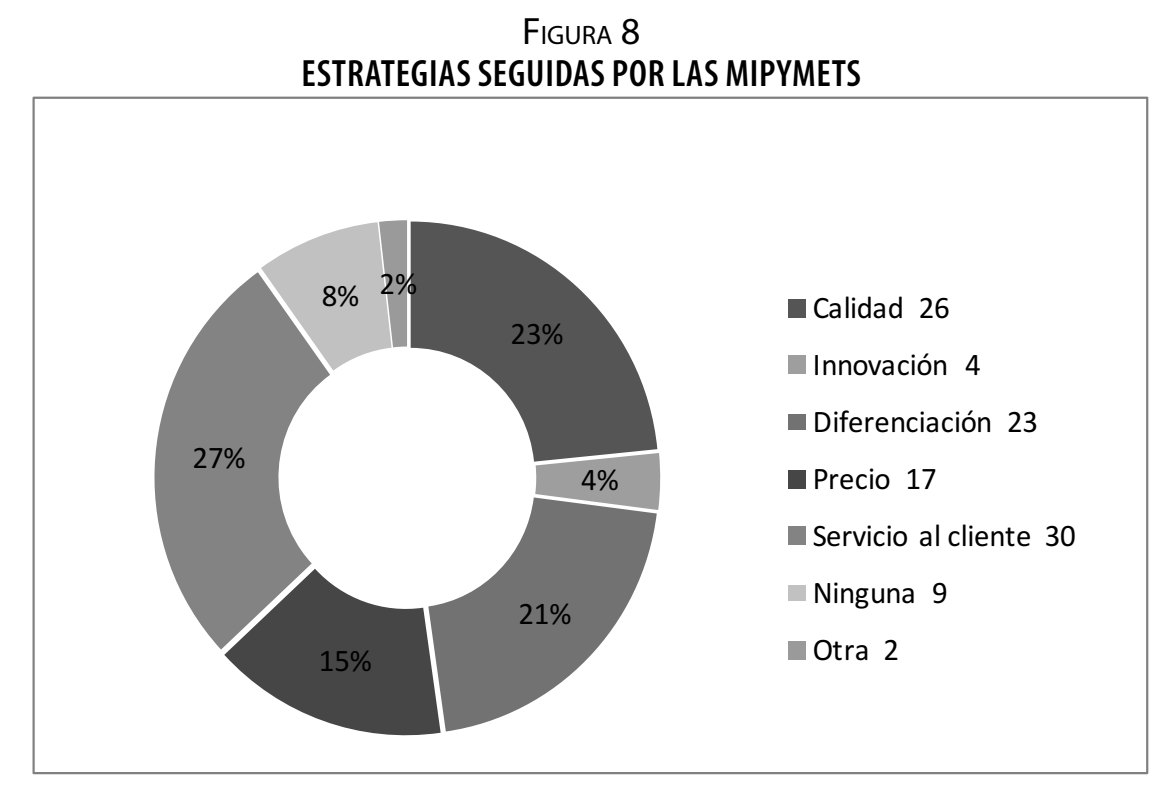

Fuente: Elaboración propia.

tegia, persigue la satisfacción del cliente o el servicio posventa pero, en sí, están muy relacionadas con el servicio al cliente. El 4\% señala que su estrategia se basa en la innovación de la organización, un bajo resultado en tan relevante factor. Las estrategias más seguidas son el servicio al cliente y la calidad, $27 \%$ y $23 \%$, respectivamente. Los dirigentes requieren una visión y misión orientadas al logro de una estrategia de negocio. Estos puntos ya se discutieron y toman mayor fuerza al determinar la falta de gestión estratégica (Figura 8).

Analizando las capacidades administrativas y estratégicas presentes en las MIPYMET, se determina que del total de dirigentes, un $43.1 \%$, únicamente dispone del título de Bachiller en educación media. Es indispensable que este sector de pequeños empresarios reciba atención de sus necesidades de formación y capacitación, para que las empresas logren mayor crecimiento y se mantengan en el mercado. La necesidad es más destacada para el 13.9\% que solo obtubo su título de primaria. Esta informa- ción será utilizada al momento de plantear el plan de mejoramiento y capacitación, objetivo fundamental de la investigación.

No hay que dejar de lado que, aun presentando la limitación de formación profesional de los empresarios de las MIPYMET, estas personas son emprendedoras, esforzadas y comprometidas con su negocio. Aquí radica la importancia de que el Estado suministre ayuda verdadera al sector y que le permita mejorar su operatividad.

El coordinador de la oficina del MEIC en Pérez Zeledón argumenta que los dirigentes actuales de las micro, pequeñas y medianas empresas del sector tienen una parcial formación empresarial que las faculte en el desarrollo de sus organizaciones. Además, ratifica el hecho de que existe un bajo nivel de profesionalismo en los jerarcas de las entidades. El señor Jaime Cervantes, de la oficina de la Cámara de Comercio, confirma esta información al responder que el nivel de profesionalismo es medio y su formación empresarial se ha dado parcialmente. 


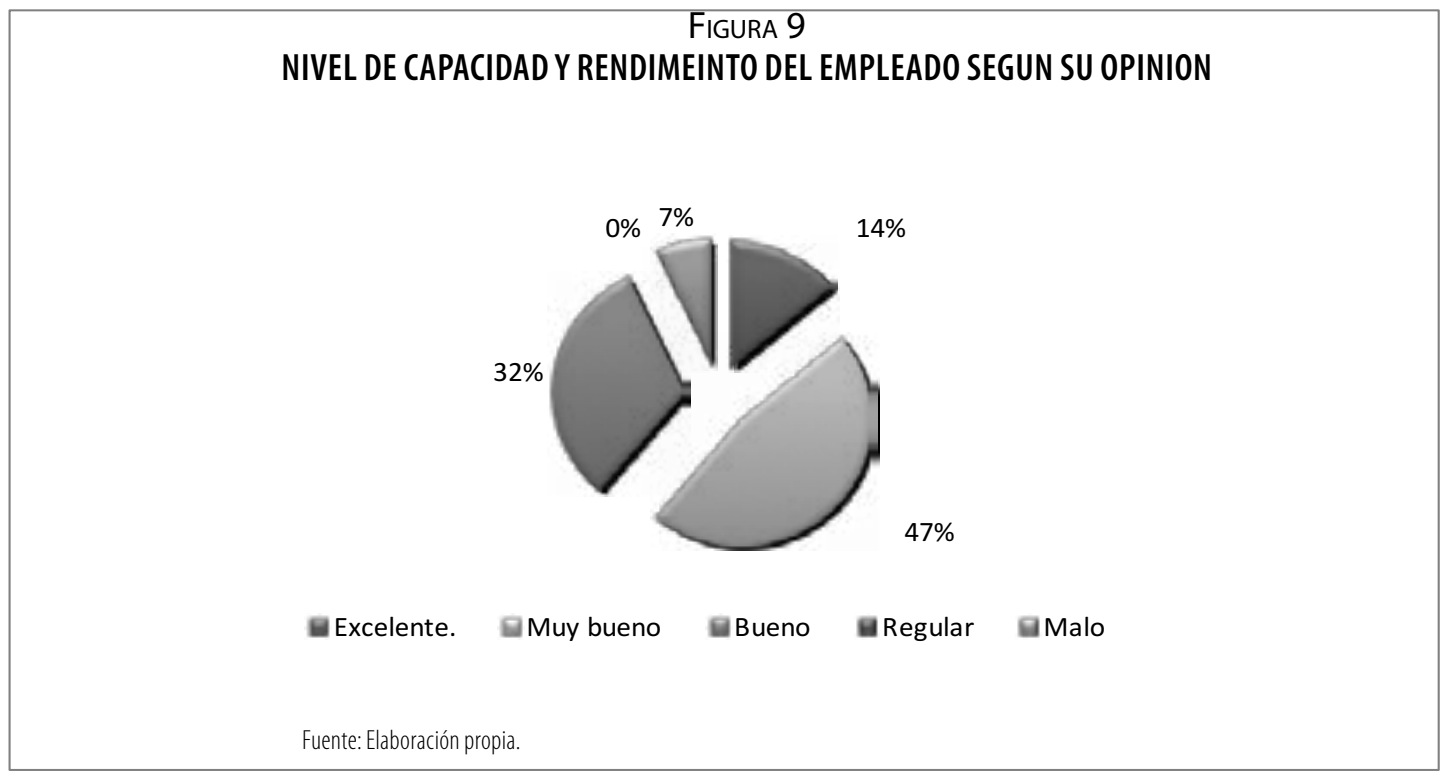

Se logra concluir, con ayuda de la información gráfica que existe, una alta capacidad y el mejor de los rendimientos de la mayor parte de los empleados. El 61\% de estos garantiza a la organización un nivel excelente y muy bueno. Al contar con un personal capaz en su accionar y con el compromiso de brindar un buen rendimiento en sus funciones, la empresa tiene la capacidad para realizar una gestión efectiva de su negocio y estrategia (Figura 9).

Otro aspecto al analizar las capacidades de toda empresa es el uso adecuado de sus recursos financieros y el manejo del financiamiento de la organización. Se consultó al dirigente sobre la fuente principal de financiamiento para la creación y sostenibilidad de la empresa. Se recabó que 49 de ellos trabajan empleando sus ingresos propios, lo que hace pensar que la empresa es rentable y se maneja de forma solvente. Además, 38 de las empresas recurren a préstamos bancarios para hacer frente a sus negocios y seguir operando, este sector expresa que, a nivel nacional, existen muchos obstáculos para acceder a créditos y que los requisitos son exagerados. La minoría recurre a ayudas familiares y a préstamos a otras empresas del mismo sector económico.

La Figura 10 detalla que más del 50\% de las empresas obtienen ganancias de más de 600 000 colones. Algunas empresas tienen un ingreso reducido en comparación con otras del sector. Esto puede dificultar la adecuada gestión administrativa y estratégica y puede repercutir en la decisión de no invertir en innovación, tecnología y modernización.

La Figura 11 ratifica que, de forma mayoritaria, el logro de estabilidad, eficiencia y eficacia se cumple en un nivel intermedio en porcentajes de $58.3 \%, 55.6 \%$ y $61.1 \%$, respectivamente. Las empresas cuentan con la capacidad administrativa de alcanzar sus objetivos, metas y resultados. Las que lo logran en un nivel bajo deben establecer mecanismos de mejoramiento que les permita mejorar su nivel. De igual forma, solo 31.9\% logra una alta estabilidad; el 13.9\% una alta eficiencia y un $12.5 \%$ la alta eficacia.

Según los datos de la Figura 12, un 8.7\% de las empresas emplean información externa. Un 16.5\% utiliza información global, mientras que 
FIGURA 10

RANGO DE INGRESOS DE EMPRESAS

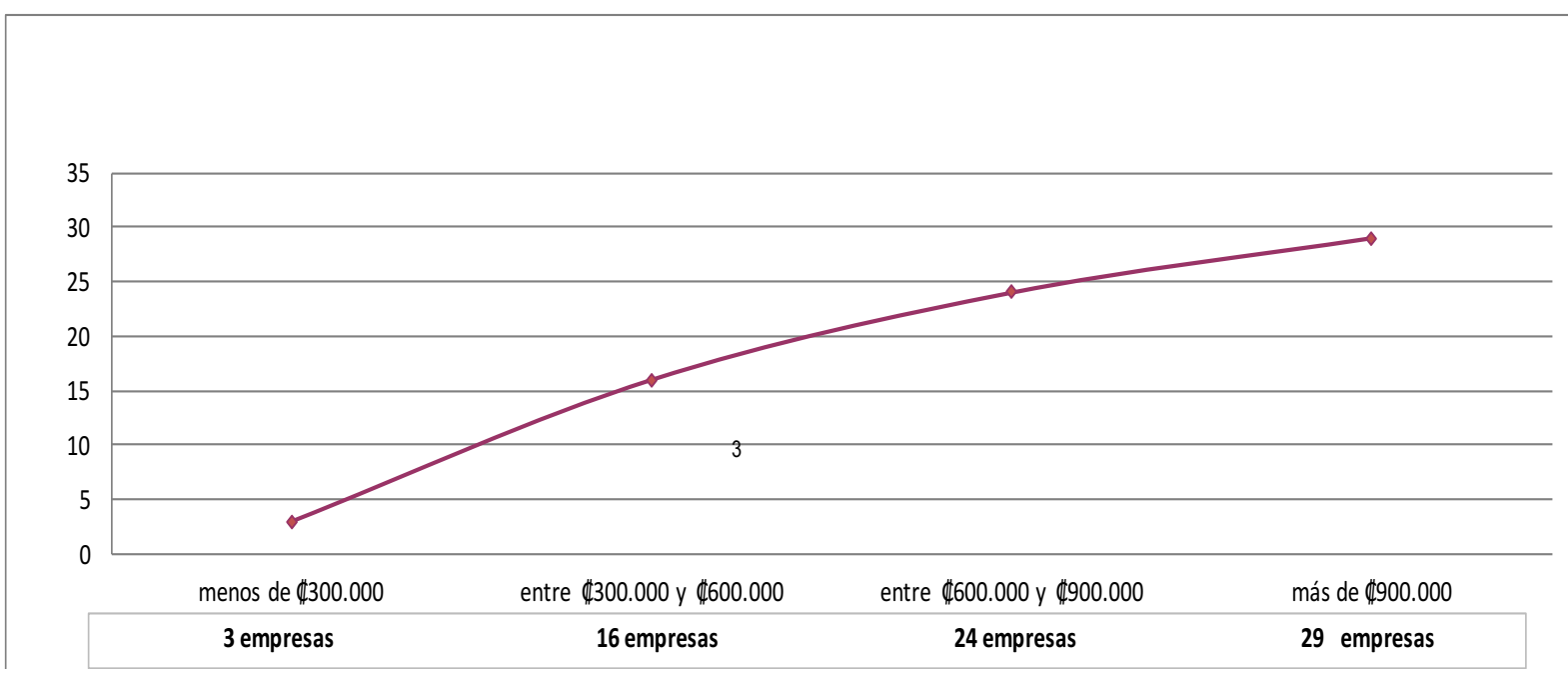

Fuente: Elaboración propia.

FIGURA 11

GRADO DE ESTABILIDAD, EFICIENCIA Y EFICACIA DE LAS EMPRESAS

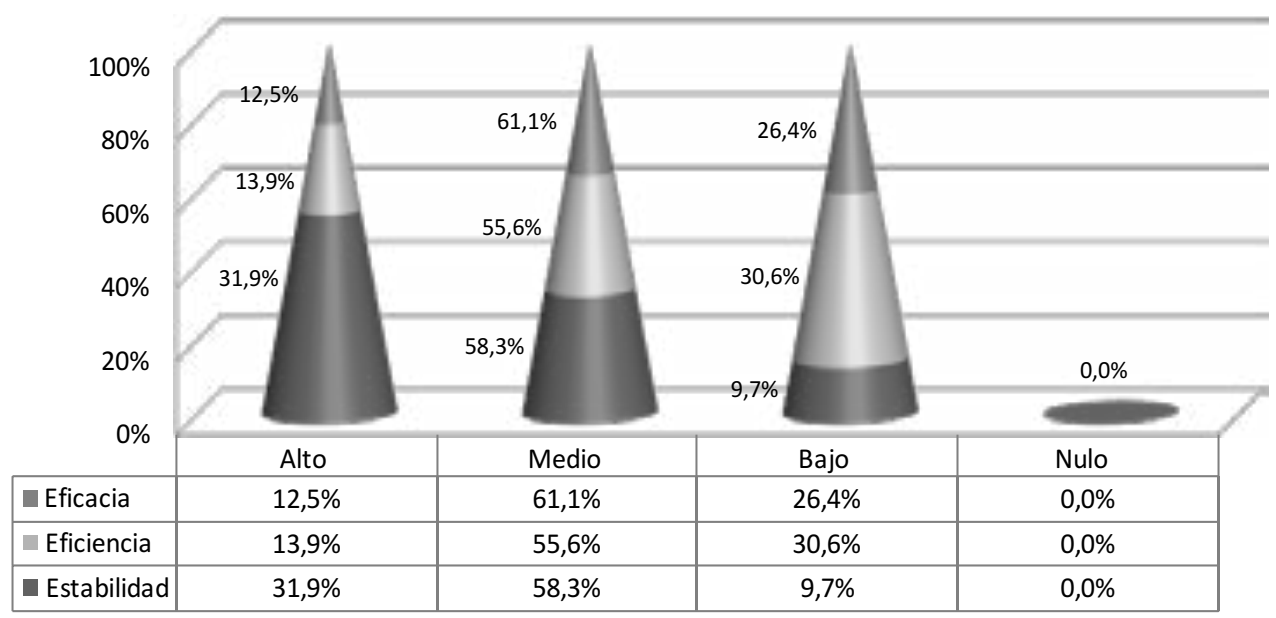

Fuente: Elaboración propia. 


\section{FIGURA 12 \\ TIPO DE INFORMACIÓN UTILIZADA PARA FIJAR LA ESTRATEGIA}

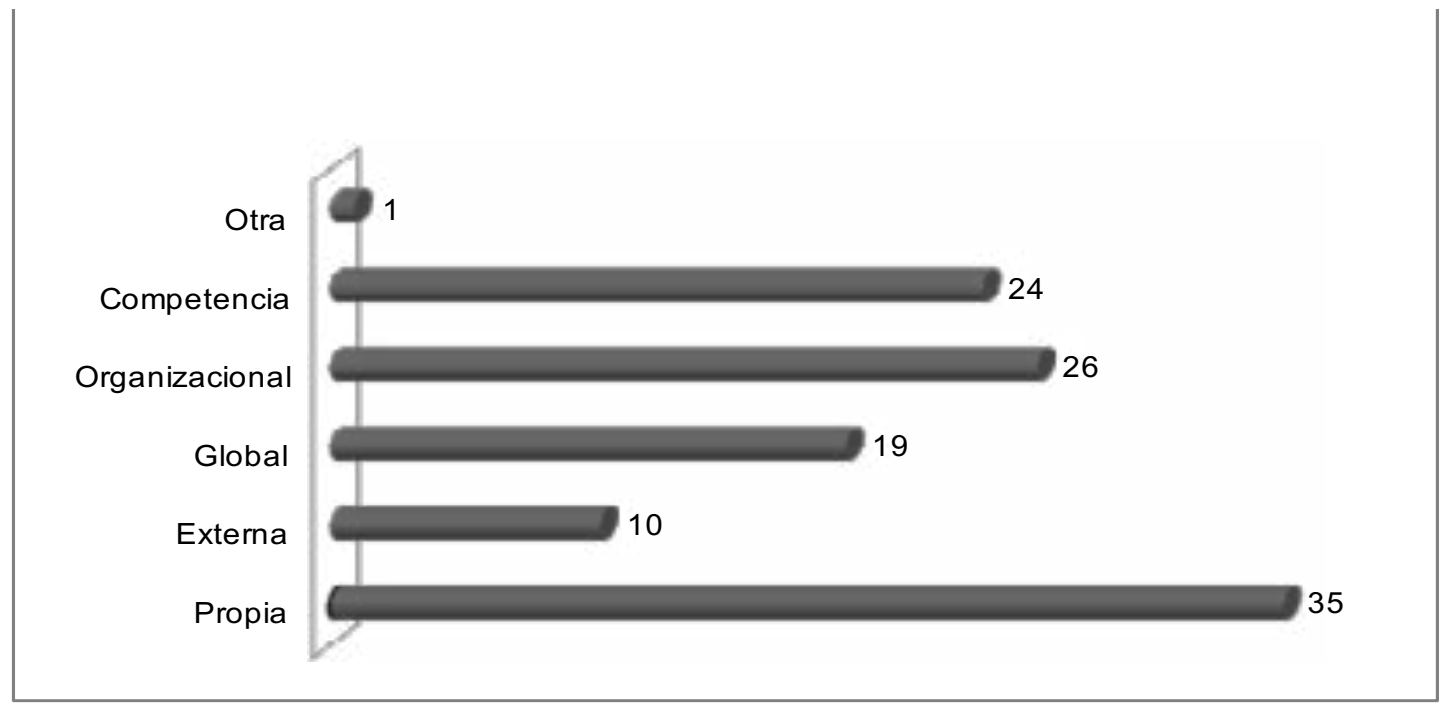

Fuente: Elaboración propia.

un 53\% emplea información propia y organizacional. Cabe destacar que el entorno competitivo y globalizado exige que las empresas utilicen la mayor cantidad de información para la toma de decisiones, la planeación y todas las funciones administrativas. Aquí radica la importancia de aprovechar el flujo proveniente del mercado; sin embargo, se aprecia que en un bajo número está utilizando la información global.

Se puede deducir que existe una reducida capacidad de las MIPYMET para utilizar la información global. Lo anterior puede tener su explicación en la limitada estructura con que cuentan las microempresas, donde no existen oficinas específicas encargadas de realizar investigación y manejar dicha información. De igual manera, la reducida formación empresarial puede limitar el uso de los datos del mercado y las organizaciones no están logrando aprovechar este recurso que se genera de forma gratuita para todos.

Fue importante, también, analizar el nivel de comunicación de las diferentes empresas tu- rísticas con la oficina del MEIC y la Cámara de Comercio. Según los coordinadores de ambas oficinas, este nivel de entendimiento y transferencia de información se da de manera media entre los involucrados.

La globalización impacta la forma en que se gestionan los negocios de la organización. Debido a esto, constantemente las empresas cambian su accionar ante las nuevas exigencias del mercado, los cambios en los gustos de los consumidores y ajustes propios de la competitividad. Una forma en que la micro, pequeña y mediana empresa puede gestionar adecuadamente sus negocios es a través de las alianzas estratégicas con otras organizaciones. Estas alianzas brindan la oportunidad para que dos o más pequeñas empresas logren competitividad, al compartir costos y reducir gastos, lograr apoyo publicitario y un aumento en la productividad.

Al realizar la consulta a los coordinadores de las oficinas estatales participantes de la investigación sobre la importancia de las alianzas estratégicas para las MIPYMET, estas asegura- 
ron que, si los pequeños empresarios trabajan conformando alianzas con otras instituciones y empresas, lograrían un mejor aprovechamiento de las oportunidades del mercado. Se observa que un alto porcentaje de las empresas que forman parte de la investigación no cuentan con alianzas estratégicas definidas y solo un número reducido de estas, está en proceso de su conformación. Este dato denuncia la falta de interés del sector en formar estas alianzas o la poca capacidad de los pequeños empresarios en trabajar en conjunto con otros empresarios. El tema debe ser tratado como de suma importancia, ya que el dirigente debe entender que este tipo de estrategias trae beneficios mutuos, colaboración y oportunidades de desarrollo.

Hasta este punto existen evidencias de que muy pocas de las micro y pequeñas empresas logran una excelente gestión de sus negocios y, por la observación realizada durante la investigación, se requiere de mejora, innovación y diferenciación de las ofertas brindadas. Pese a esto, los dirigentes en un $17 \%$ y un $29 \%$ sostie- nen que su competitividad es de media a alta. De los siguientes aspectos que se analizaron depende determinar si es necesario el aumento de la competitividad del sector (Figura 13).

Al analizar estos aspectos con ayuda de la oficina del MEIC y la Cámara de Comercio, se llegó a la conclusión de que las MIPYMET tienen un grado de medio a bajo en adaptabilidad y respuesta a los cambios que se originan por el impacto de la globalización. De igual manera, al presentarse cambios en el mercado sobre gustos y necesidades, estas entidades responden con un bajo o medio nivel de efectividad.

La adaptabilidad de las empresas ante el entorno competitivo es de vital importancia para su posicionamiento; la investigación da como resultado que la mayoría de entidades se adaptan rápido a los cambios dentro del mercado. Es clave que este aspecto se mejore y aumente el grado de dinamismo de las empresas, con más razón las de este sector tan competitivo.

FIGURA 13

NIVEL DE COMPETITIVIDAD DE LAS EMPRESAS SEGUN SUS DIRIGENTES

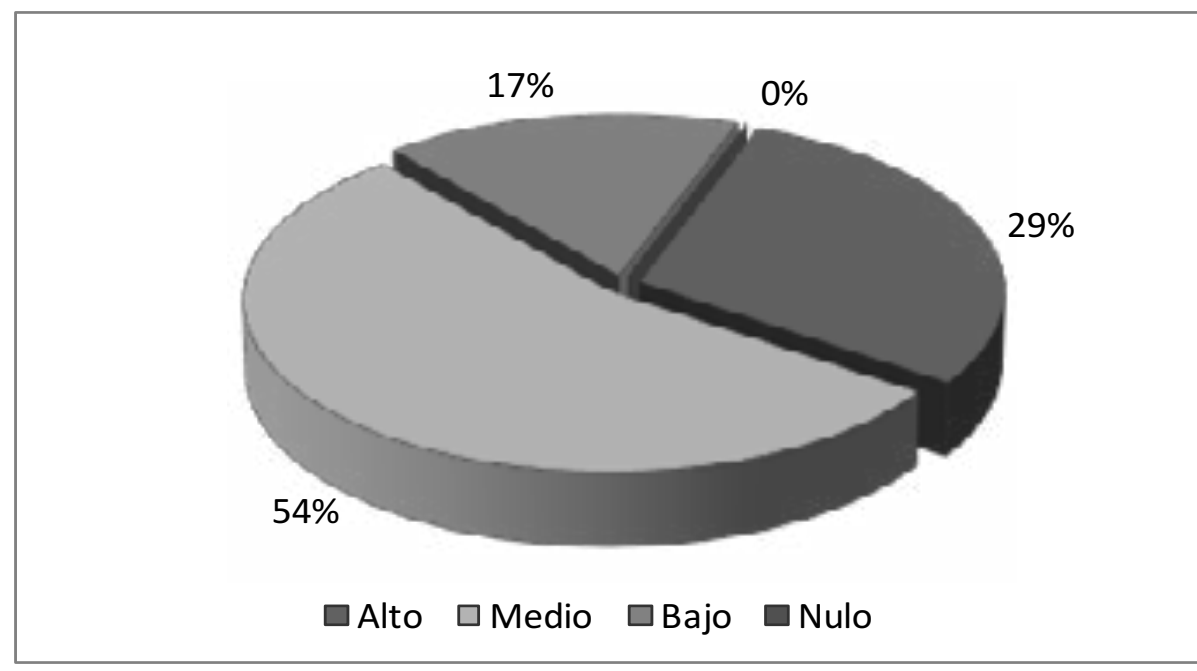

Fuente: Elaboración propia. 
Falta mejorar la capacidad del sector. Una manera de impedir la obsolescencia del negocio es implementar una mejora continua que responda a la información de un mercado que cambia de manera constante. Otro punto para recalcar es que las MIPYMET cuentan con la capacidad administrativa y estratégica de que los cambios, mejoras y cualquier implementación planeada sean de fácil incorporación al estilo de trabajo de la compañía.

Un punto adicional estudiado es la participación de los dirigentes de la micro, pequeña y mediana empresa en actividades y programas de capacitación establecidas por diferentes en-

\section{FIGURA 14 \\ CANTIDAD DE EMPLEADOS QUE HAN PARTICIPADO EN ACTIVIDADES O PROGRAMASA DE CAPACITACIÓN DE ENTES ESTATALES}

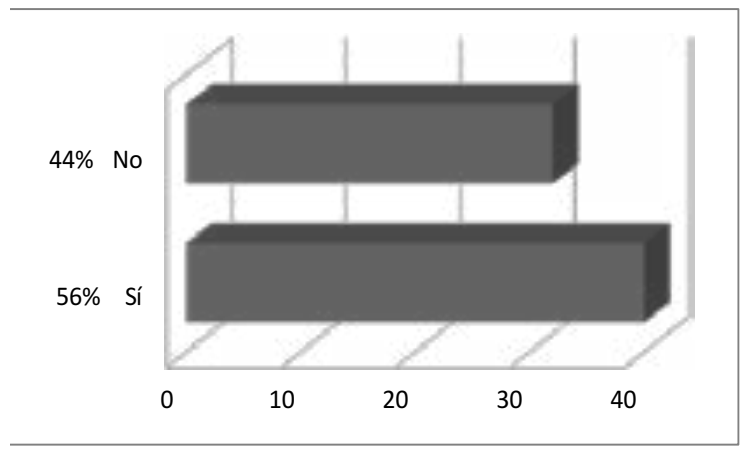

Fuente: Elaboración propia.

tes estatales. Más de la mitad de dirigentes (40) ha formado parte de alguno de estos programas de inducción y capacitación. Esto quiere decir que el 56\% de los responsables de la gestión administrativa y estratégica han recibido ayuda a nivel nacional. Al hacer la observación se detalla que la institución con mayor número de capacitaciones realizadas, en las cuales han participado estos dirigentes, es el Instituto Nacional de Aprendizaje (Figura 14).
Los individuos que han recibido, en algún momento, capacitación por parte de entes estatales aseguran que estas se han reducido y que son necesarias para mejorar la forma en que se gestiona el negocio. Para esta investigación es clave proporcionar un plan que involucre una capacitación del personal desde los niveles altos de la administración hasta los niveles bajas de los trabajadores. Las empresas que no han participado, el 44\%, opinan que hace falta oferta de estos programas y que estarían dispuestas a participar en el futuro. Lo anterior se muestra como una capacidad de las empresas en participar en programas orientados al mejoramiento.

Los dirigentes tienen la responsabilidad de que el 44\% de empleados con formación parcial cuenten con la oportunidad de capacitarse y participen en actividades de profesionalismo y entrenamiento en los procesos llevados a cabo para la organización. De la misma manera, el $18 \%$ que responde negativamente a la interrogante, debe ser partícipe en los programas, con el fin de que el 100\% del personal de las MIPYMET esté altamente dotado de herramientas técnicas y conocimiento que les faculte la toma de decisiones efectiva (Figura 15).

Como se aprecia en la Figura 16, el 57\% de los dirigentes y el $49 \%$ de los empleados encuestados opinan que, efectivamente, el cantón de Pérez Zeledón ofrece oportunidades tangibles para el desarrollo de las MIPYMET. De forma parcial, un $28 \%$ de dirigentes y $25 \%$ de trabajadores creen que las oportunidades son generadas por el territorio.

Se descifra que el cantón, por sus recursos y características, representa una fortaleza externa para las organizaciones. Muchos pequeños empresarios visualizan oportunidades en los recursos naturales del cantón, por lo que basan nuevas empresas aprovechando estos recursos.

Al realizar la consulta, un $78 \%$ estuvo de acuerdo en asegurar que el turismo represen- 
FIGURA 15

CANTIDAD DE EMPRESASQUE CUENTAN CON PERSONAL CAPACITADO Y ENTRENADO EN SUS FUNCIONES

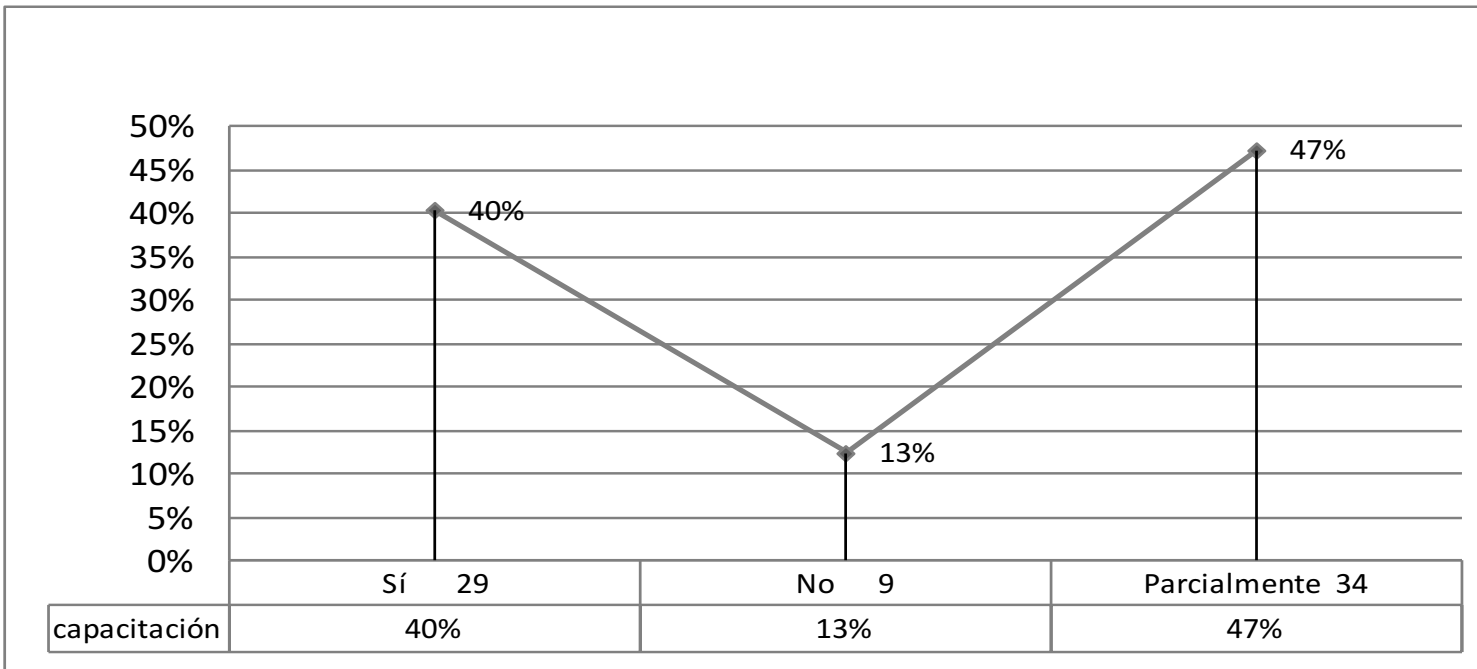

Fuente: Elaboración propia.

FIGURA 16

¿CONSIDERAN QUE PÉREZ ZELEDÓN OFRECE OPORTUNIDADES PARA EL DESARROLLO DE LA MIPYME? DIREIGENTES VS EMPLEADOS

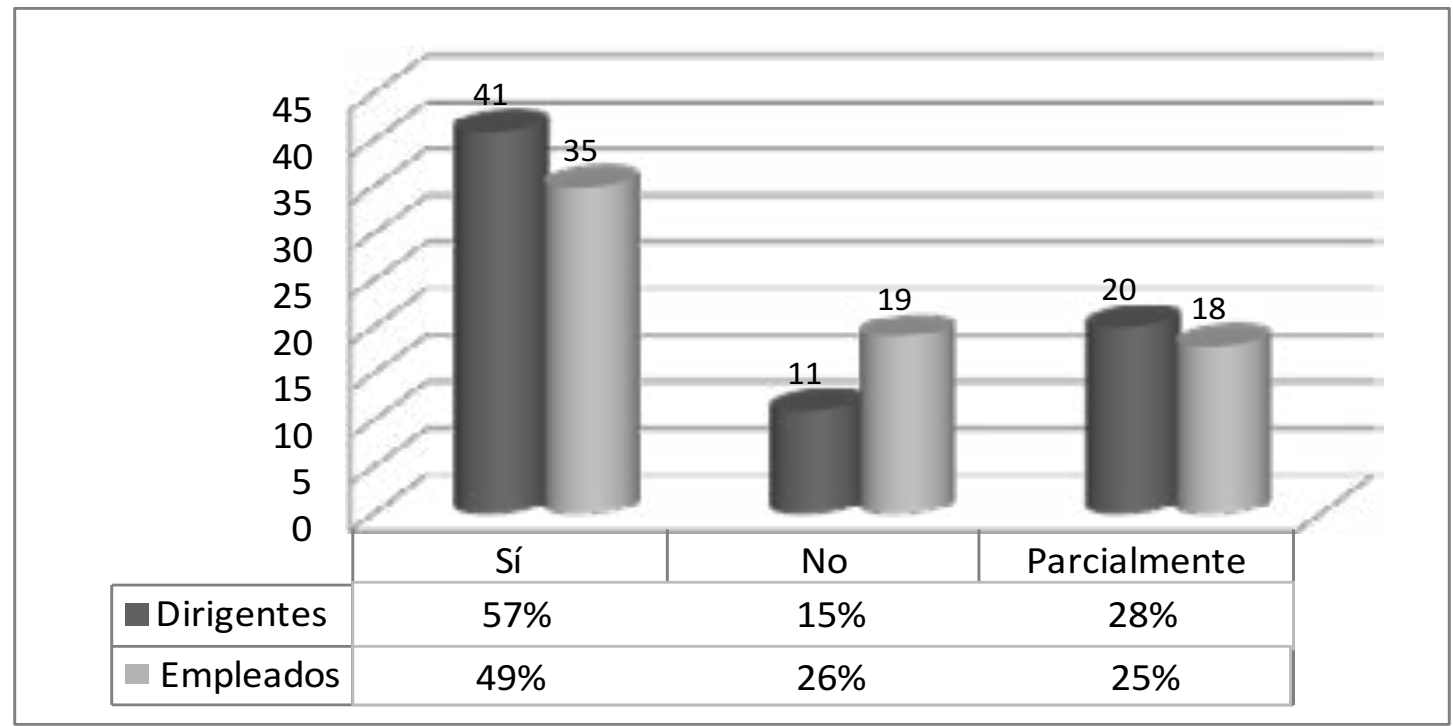

Fuente: Elaboración propia. 


\section{GRADO DE IMPORTANCIA QUE OTORGAN LAS MIPYMET AL TURISMO LOCAL}

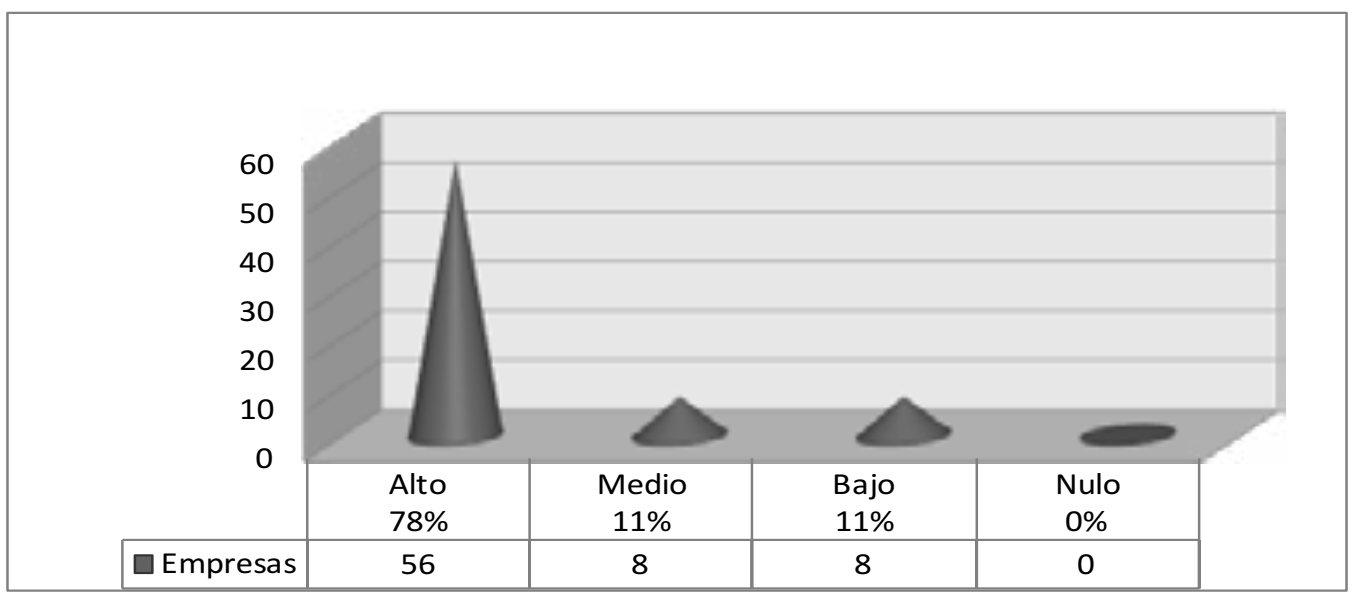

Fuente: Elaboración propia.

ta una alta importancia para el crecimiento y sostenibilidad de sus organizaciones. El potencial turístico analizado en el punto anterior demuestra cómo el cantón proporciona este recurso al empresario y que, gracias a él, el mayor porcentaje de MIPYMET desarrolla su oferta y gestiona sus negocios. El aprovechamiento de las características del territorio depende exclusivamente del empresario y de su capacidad en transformarlas en fortalezas para la empresa (Figura 17).

Se considera una fortaleza que el $81 \%$ de los dirigentes de la micro, pequeñas y medianas

FIGURA 18

NIVEL DE IMPACTO DEL MERCADO GLOBALIZADO EN LA GESTION ADMINISTRATIVA

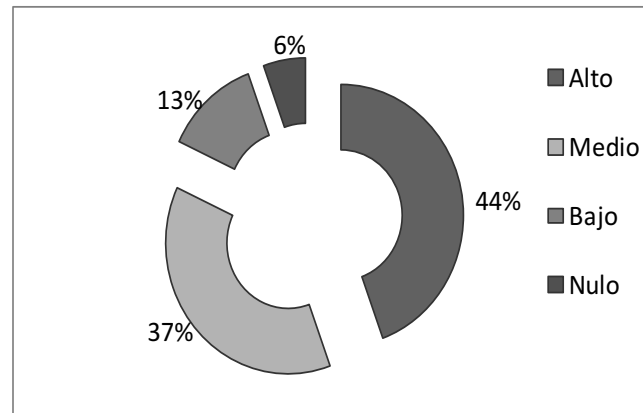

Fuente: Elaboración propia. empresas tengan presente que la globalización, la generación permanente de información y constantes cambios que se originan en el mercado repercutirán en un alto nivel en la gestión administrativa y estratégica seguida por las entidades. El restante porcentaje debe implementar un pensamiento innovador y saber que para lograr competitividad, crecimiento y desarrollo organizacional y económico es indispensable trabajar de la mano con la globalización (Figura 18).

La Figura 19 detalla las cuatro necesidades principales de las empresas. Se aprecia que un 21.4\% de los responsables de la gestión administrativa y estratégica requieren capacitación y actualización de conocimientos. Por su parte, 20.7\% de los empleados plantea la capacitación como la principal necesidad personal.

En segundo lugar, se encuentra que $18.6 \%$ de dirigentes y $19.3 \%$ de empleados coinciden en que las MIPYMET necesitan formar alianzas estratégicas de trabajo conjunto. En tercer lugar de prioridad, $16.7 \%$ de los dirigentes opina que se requiere mayor apoyo publicitario; de igual manera, un 14\% de sus empleados toma 


\section{FIGURA 19 DETERMINACIÒN DE NECESIDADES PRESENTES}

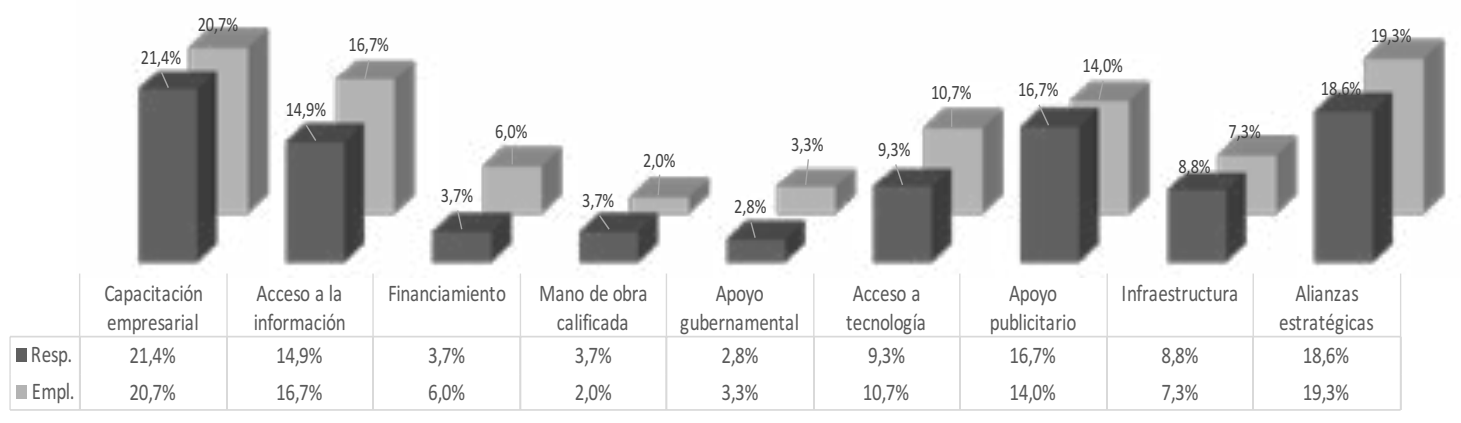

Fuente: Elaboración propia.

este aspecto como necesario para la empresa. Como último aspecto relevante, el $16.7 \%$ de los empleados considera que requiere mayor acceso a la información del entorno y lo ratifica el 14.9\% de los dirigentes de las empresas.

Se llega a la conclusión de que la capacitación en todos los niveles de la organización representa una debilidad y necesidad latente para las micro, pequeñas y medianas empresas turísticas en Pérez Zeledón. Otra debilidad descifrada es la carencia de alianzas estratégicas con otras organizaciones, los dirigentes trabajan de forma individual y no gestionan asociaciones con otras entidades.

Es de recalcar que solo un bajo porcentaje de empleados no indicó ningún tema como necesario para la empresa. Entre los temas de mayor relevancia para ser incorporados están: el idioma, servicio al cliente, manejo de software, manejo de información, emprendedurismo y la comunicación. Estos datos son vitales para la determinación de capacitaciones posteriores a la investigación sobre el papel de las pequeñas empresas.

En la Figura 20 se suministran los resultados del análisis. La opción 4, sobre satisfacción del cliente, es percibida en un 15.2\% como fortaleza; la opción 5, de calidad de la oferta, en un
14.1\%; las opciones 7 y 8, de trabajo en equipo y compromiso con un $15.2 \%$ y $12.4 \%$, respectivamente. Estos cuatro puntos son las más relevantes fortalezas identificadas en las micro, pequeñas y medianas empresas.

El 58.3\% del personal entrevistado indica que el grado de innovación de la entidad es bajo. Por otro lado, el $65.3 \%$ opina que el grado de estabilidad económica es medio. Un bajo porcentaje, 34.8\% piensa que sus empresas cuentan con un alto nivel de innovación y estabilidad (Figura 21). La información ratifica el resultado obtenido sobre las debilidades empresariales, donde la innovación forma parte de las necesidades a superar.

Algunos de los aspectos resultantes de la entrevista al coordinador del MEIC y del ejecutivo de la CCTIA son los siguientes:

- Las micro, pequeñas y medianas empresas se caracterizan por dar estabilidad a un núcleo familiar y por contar con dirigentes emprendedores que han sabido salir adelante con pocos recursos y muchos obstáculos.

- Uno de estos obstáculos es la burocracia y variedad de trámites que les dificulta acceder a créditos y ayudas y la percepción de recibir poca colaboración por parte del estado 
FIGURA 20

FORTALEZAS Y DEBILIDADES DETERMINADAS POR LOS DIRIGENTES MIPYMET

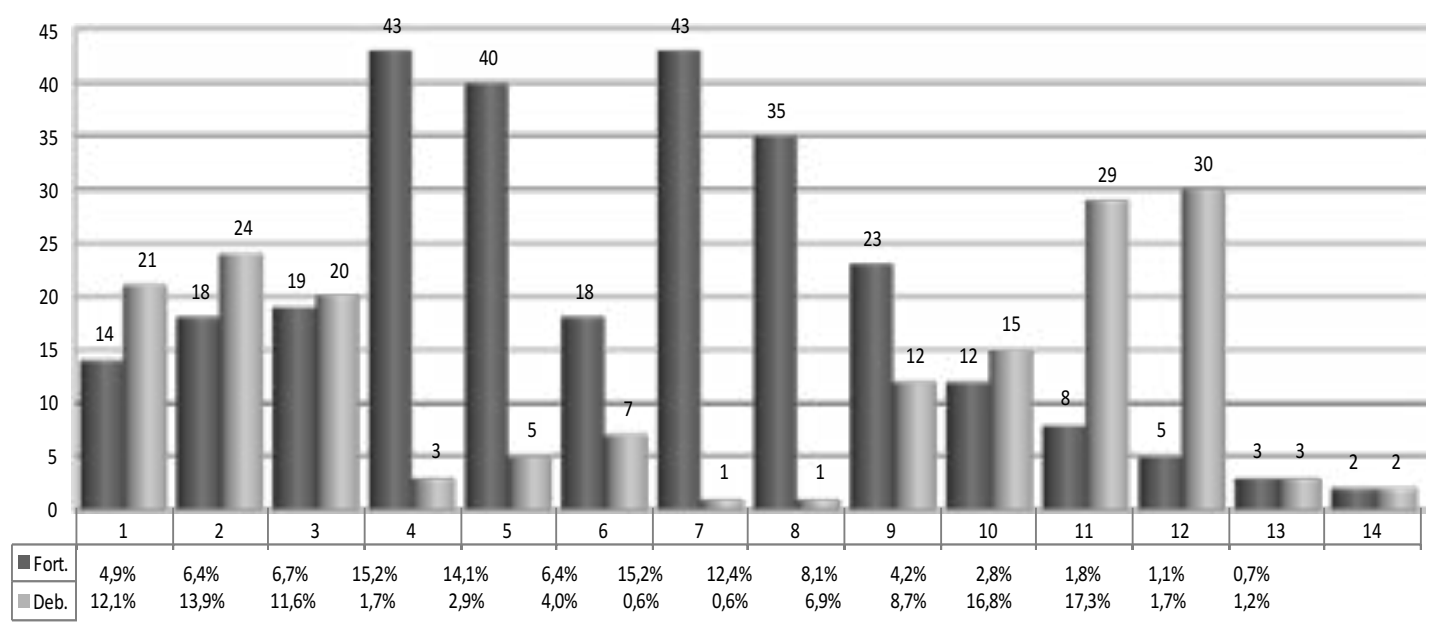

Fuente: Elaboración propia.

FIGURA 21

GRADO DE INNOVACIÒN, ESTABILIDAD ECONÒMICA Y ORGANIZACIONAL, SEGÚN CRITERIO DEL EMPLEADO

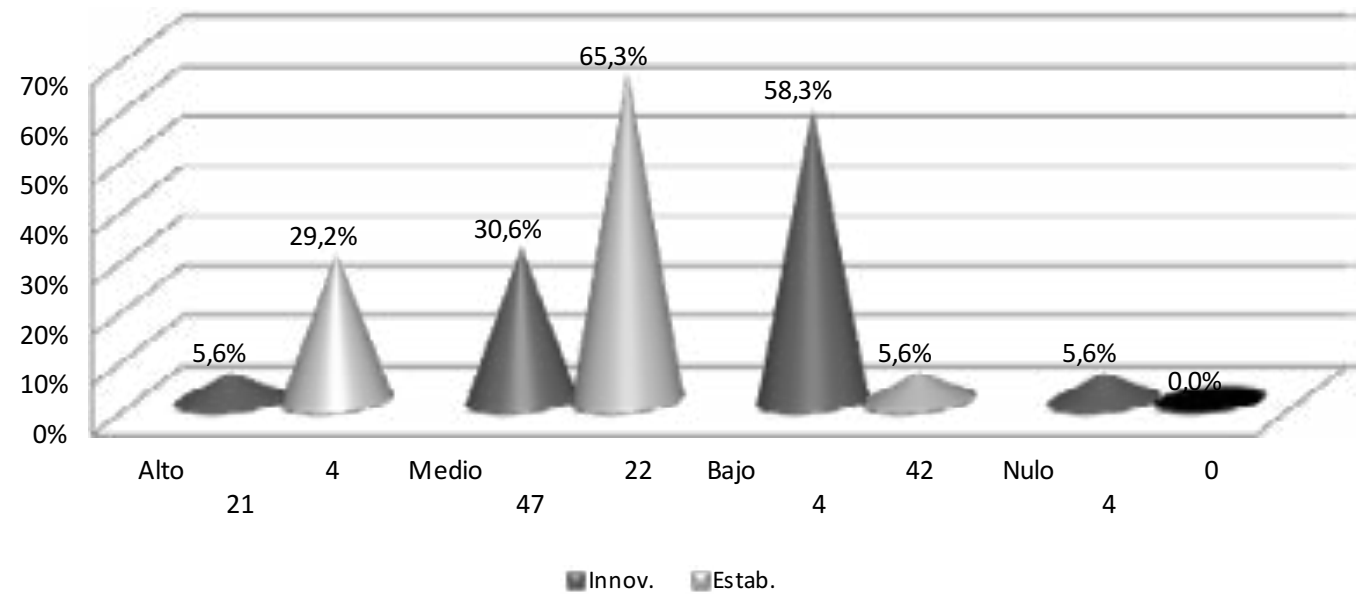

Fuente: Elaboración propia. 
nacional. Estas empresas presentan un bajo nivel de administración y comercialización de sus productos.

- La realidad de ser empresas familiares puede ser vista como una fortaleza del sector, pues representa una opción para brindar empleo a toda una familia, proporcionarle solvencia económica, bienestar, mejor calidad de vida y un crecimiento profesional de aquellos que lo logran. Esto hace que tengan la fortaleza, según los entes entrevistados, de ser excelentes productoras de bienes y servicios.

- Los pequeños empresarios que conducen estos negocios son personas con una visión emprendedora, con ideas claras y la iniciativa para llevarlas a la práctica, su dedicación a la gestión es casi de tiempo completo y la aptitud para superar obstáculos y barreras es sobresaliente. Dadas estas características, es de vital importancia potenciar el recurso humano y desarrollar sus empresas.

- $\quad$ Las principales necesidades del sector son: mejorar los mecanismos de mercadeo, tener mayor acceso a financiamiento y crédito, mejorar la empresariedad, tener capacitación en temas de gestión y planificación, actualizar conocimientos, formar alianzas estratégicas, mejorar el manejo de información y mejorar la mejora continua de la organización.

Todas estas apreciaciones son valiosas para analizar la gestión administrativa y estratégica realizada actualmente por las micro, pequeñas y medianas empresas turísticas instauradas en el territorio de Pérez Zeledón. En el siguiente capítulo se analizarán los principales resultados y conclusiones, con el fin de brindar un plan adecuado de mejoramiento y capacitación que responda a las necesidades presentes en este sector de la economía del cantón.

\section{DISCUSIÓN}

Sobre el objetivo específico 1 se concluye que:

La mayoría de los dirigentes considera que el puesto que ocupa dentro de la empresa es de dueño y encargado. Esto evidencia que no existe una estructura ocupacional instaurada en estas entidades, por lo que no se aprecia una clasificación de puestos adecuada.

En el territorio abarcado se determinó que la gran mayoría de las empresas turísticas presentes son microempresas, con una organización plenamente familiar y un máximo de cinco empleados, entre ellos miembros del núcleo familiar. Cabe notar la actitud emprendedora de los individuos del cantón, donde por medio de la propuesta de ideas, sus familias han logrado una estabilidad económica.

Se determinó que más de la mitad de las empresas encuestadas, de forma parcial o total, no cuentan con aspectos organizacionales como: visión, misión, objetivos, políticas y normas dentro de sus organizaciones. Estos aspectos son claves para trazar las metas a corto y mediano plazo de cualquier empresa en el actual entorno competitivo y dinámico. De igual manera, si se instauran estos aspectos en la entidad, es imposible que los empleados manejen la información y estén comprometidos con las metas en común.

La gestión administrativa involucra funciones clave: planeación, organización, dirección, control, evaluación y toma de decisiones. Se concluyó, luego del análisis estadístico, que un número muy reducido de las empresas realiza todas estas funciones de manera estandarizada y estructurada. La planeación y dirección administrativa son consideradas como las tareas más desarrolladas por los dirigentes; sin embargo, se presentan de forma aislada del resto de las funciones señaladas. 
Analizando la competitividad del sector turismo, se observa que solo 22 entidades del total encuestado consideran al mercado global en la determinación de sus ofertas de bienes y servicios. Se determina que los pequeños empresarios aun mantienen un pensamiento local o regional al momento de considerar estrategias, exigencias y necesidades y que piensan en clientes cercanos a su localización.

La gestión estratégica es vital para lograr competitividad y estabilidad. Ante esto, se identificó que $29 \%$ de empresas, un reducido porcentaje, realiza una adecuada gestión de su estrategia de negocios. El resto de las entidades trabaja con ideas y objetivos a lograr sin la ejecución de un plan de negocio determinado. Muchas mencionan seguir estrategias en precio, calidad o satisfacción, sin embargo, no realizan una planificación y planeación estratégica de forma estructurada y periódica. Las estrategias seguidas por aquellas organizaciones que respondieron que efectivamente realizan esta función son basadas en: servicio al cliente, diferenciación y calidad.

\section{En cuanto al objetivo específico 2, se obtuvo que:}

Según el nivel de escolaridad de los dirigentes de las MIPYMET como punto de partida al evaluar sus capacidades, la mayor cantidad de ellos cuentan únicamente con una secundaria completa; en menor cantidad se encuentran los poseedores de títulos universitarios. Esto permite concluir que existe poca formación empresarial y profesional de los responsables de la gestión administrativa.

A pesar de la falta de profesionalismo de muchos de los dirigentes de las micro, pequeñas y medianas empresas turísticas, se debe destacar que estos pequeños empresarios han tenido una actitud emprendedora, esforzada y comprometida. Casi la totalidad de ellos han incursionado en la formación de sus empresas con ideas que se originan de una oportunidad en el mercado, sin haber tenido inducción y capacitación de entes estatales u organizaciones de apoyo a las PYMES.

Las dos principales fuentes de financiamiento de las MIPYMET son, en primer lugar, los ingresos propios $y$, en segundo, los préstamos bancarios. Se deduce que existe una capacidad manifiesta de hacer frente a los gastos operativos por medio de las utilidades logradas. Es importante consolidar un crecimiento adecuado y una estabilidad de todo el sector, que les permita sostenibilidad por medio de su funcionamiento y no depender de terceros para su financiamiento. Se determinó que la mayoría de organizaciones tiene un ingreso mensual superior a los $\$ 600000$.

Con respecto al grado de estabilidad, eficiencia y eficacia organizacional, se logra determinar que el nivel manejado dentro de las empresas analizadas es intermedio. Poca cantidad de estas entidades asegura tener un alto grado de eficiencia y eficacia operativa. Este elemento permiten visualizar una limitada capacidad de gestión en el logro de los objetivos y resultados y en la utilización de los recursos financieros y organizacionales.

Con respecto al manejo de información, otra conclusión importante es que la minoría utiliza información proveniente del entorno global. Algunos dirigentes expresaron usar únicamente información propia y, en otros casos, datos de la competencia local. Se observa que existe poco interés de obtener información global, lo que repercute negativamente, ya que en la actualidad toda organización debe incorporar estrategias, procesos, negocios e ideas provenientes de cualquier parte del mundo. Se dice que las empresas deben imitar aquellas cosas que han representado beneficios para otras organizaciones.

El 67\% de las empresas analizadas no maneja alianzas estratégicas con otras organizaciones. 
Este dato es relevante para concluir que las MIPYMET trabajan de forma individual y aislada con otros empresarios. Actualmente, muy pocas de ellas obtienen beneficios mutuos al trabajar por medio de estas alianzas de trabajo. Las alianzas permiten compartir costos, inversiones y gastos; de igual forma, permiten un crecimiento, una mejora de la oferta y la calidad.

Los dirigentes sostienen que sus empresas logran un nivel de medio a alto de competitividad en el mercado donde se desarrolla el negocio. Sin embargo, por medio del trabajo de campo se concluye que esta percepción involucra solo aspectos locales, los dirigentes no se comparan con empresas a nivel nacional o internacional. En lo que respecta a bienes y servicios turísticos, las organizaciones deben tener una visión global de trabajo y no tener únicamente un criterio local.

El fenómeno de la globalización impacta en todas las empresas por igual, sin diferenciar tamaños o estructuras, de aquí lo vital de medir el grado de adaptabilidad de la micro y pequeña empresa. Ante el panorama, este estudio demuestra que las MIPYMET manejan un grado intermedio de adaptabilidad a los cambios que se originan en el entorno. Si la empresa maneja poca información global, se basa en un mercado local y compite sin visión y misión claras, es de esperar que tenga poca adaptación de los cambios que llegan con la globalización. Cabe resaltar que el personal de las empresas demuestra no tener temor ante la globalización.

Una gran parte de los dirigentes actuales, no han participado en actividades o programas de capacitación brindadas por entes estatales. La necesidad de este tipo de capacitación y actualización toma validez al requerirse de un mejoramiento en la gestión administrativa y estratégica que llevan a cabo las organizaciones.

Los dirigentes aseguran que la capacidad del personal que trabaja para sus empresas es de buena a muy buena. Esto hace concluir que es necesario mejorar sus capacidades a través de la dotación de herramientas técnicas y de nuevos conocimientos que potencien el talento humano, que permita un crecimiento del rendimiento y de logro de objetivos.

En el objetivo específico 3, se concluye que:

El territorio del cantón de Pérez Zeledón ofrece oportunidades adecuadas para el establecimiento y desarrollo de nuevas micro, pequeñas y medianas empresas turísticas. Su alta biodiversidad, el clima tropical, existencia de zonas de exuberante belleza y sus recursos naturales, hacen del territorio un sitio con potencial turístico que puede ser explotado por los pequeños emprendedores.

Los dirigentes de las MIPYMET y sus empleados brindan un alto grado de importancia al turismo; este aspecto es vital para el desarrollo, pues para la economía del país el turismo representa un alto porcentaje de su Producto Interno. Las organizaciones deben trabajar en ofertas que se adecuen a los gustos y exigencias de los turistas a nivel internacional.

El logro de la eficiencia y eficacia dentro de las organizaciones es considerado como una debilidad del sector, así lo demuestran los empleados que opinan que los objetivos no se logran de forma eficiente o que se alcanzan, pero de forma parcial. De igual manera, los resultados obtenidos no van de acuerdo con una reducción de los costos operativos; por lo tanto, la eficacia no se da de forma clara.

Se determina la existencia de un reducido nivel de innovación dentro de las organizaciones, este aspecto es percibido con un grado de bajo a medio. Muy pocas de las MIPYMET, solamente aquellas clasificadas como de mediano tamaño implementan un nivel alto de innovación en sus funciones y procesos. 
El nivel de calidad de la oferta brindada a los consumidores, según sus propios dirigentes, es intermedia. Esto conduce a plantear la necesidad de que las empresas establezcan un mejoramiento global de los procesos y un profesionalismo de sus trabajadores, que permita obtener un bien o servicio de la más alta calidad.

Se evaluó el impacto que provoca un mercado globalizado en la tarea de gestión administrativa desempeñada por el dirigente. Ante lo cual, se concluye que las empresas tienen la fortaleza de tomar en cuenta los cambios, estrategias, información y tendencias que se originan en el mercado por el impacto de la globalización. Por otro lado, se concluye que hace falta mejorar el aprovechamiento de esta información para la mejora continua, innovación y crecimiento empresarial de las entidades, con el objetivo de aumentar su participación en el mercado y su competitividad.

Similar al punto anterior, los dirigentes aseguran que los programas, políticas, leyes y sistemas establecidos por el gobierno, de apoyo a las MIPYMET no repercuten positivamente en sus organizaciones. Es preocupante determinar como una debilidad el impacto de las iniciativas gubernamentales con respecto al apoyo de las micro, pequeñas y medianas empresas del país. Dichas iniciativas no llegan a los sectores más desprotegidos de la economía y mucha de la información no es clara y transparente, lo que provoca que no se aproveche como debiera.

Tanto el dirigente como sus empleados están plenamente conscientes de la necesidad de capacitación empresarial. Este hecho se transforma en una debilidad al determinar la carencia de conocimientos adecuados y actualizados en temas de gestión administrativa y estratégica. Los niveles altos de las empresas deben lograr mayor profesionalismo que los faculte en el aprovechamiento de oportunidades que se originan en el mercado.
Otra de las debilidades identificadas en este sector de la economía nacional es el poco uso de alianzas estratégicas con otras organizaciones. Este hecho se da porque los pequeños empresarios no tienen una formación de trabajo conjunto y laboran de manera aislada e individualizada. Las alianzas estratégicas forman parte vital de las grandes compañías, aprovechando sus beneficios han logrado competitividad, consolidación y estabilidad económica.

Un aspecto percibido como fortaleza de las pequeñas empresas es la infraestructura, ya que muchas cuentan con terrenos propios y no incurren en gastos de alquiler de locales para operar. Es fundamental que los dirigentes mejoren el potencial de sus terrenos y desarrollen al máximo los recursos naturales presentes en ellos.

El autofinanciamiento se determina también como otra fortaleza del sector, muchas organizaciones logran su estabilidad económica por medio de la utilización de sus propios recursos financieros. Estas empresas han hecho frente a sus operaciones utilizando ingresos propios lo que lleva a pensar que existe la posibilidad de mejorar paulatinamente.

Los temas determinados como de interés popular por parte de los empleados son: idioma, servicio al cliente, manejo de software, manejo de información y emprendedurismo. De manera concluyente, los aspectos señalados como fortalezas de las MIPYMET son: satisfacción del cliente, calidad de la oferta, trabajo en equipo, compromiso con objetivos y metas, manejo de recursos y la comunicación.

Los elementos determinados como debilidades de las MIPYMET, según el estudio, son: uso de tecnología, la innovación, el manejo adecuado de la información y la mejora continua. Además, la especialización del talento humano puede ser visualizada como una debilidad dentro de las pequeñas empresas. 


\section{RECOMENDACIONES}

De acuerdo con la realidad de cada micro, pequeña y mediana empresa, se recomienda adoptar la implementación de una adecuada clasificación de puestos. El dirigente debe dejar de visualizarse como simple dueño y encargado de la empresa para la que trabaja e iniciar una reestructuración de jerarquía, la cual empieza con la formalización de los puestos de gerencia.

Todas las empresas deben iniciar el proceso de instauración de su misión y visión de negocio. Este tema será abordado por la propuesta de mejoramiento, por lo que se promulga su importancia para la identidad de la empresa y el logro de objetivos. De igual manera, las organizaciones deben iniciar la determinación de políticas, objetivos y normas organizacionales. Las políticas sirven para crear una normativa interna y una cultura formal de trabajo, los objetivos se convierten en la razón de ser de la empresa y las normas son fundamentales para el desarrollo del negocio.

Los dirigentes de las micro, pequeñas y medianas empresas turísticas deben realizar de forma estandarizada y estructurada todas las funciones clave de la administración: planeación, organización, dirección, control, evaluación y toma de decisiones.

Para determinar la oferta de bienes y servicios, las organizaciones deben recopilar información a nivel global. Esto significa tomar en cuenta el mercado local, regional, nacional e internacional. Las empresas no deben basar sus ofertas con un criterio local simplemente, ya que dejarían de tener competitividad a nivel mundial.

Como parte de la gestión desarrollada, las MIPYMET deben desempeñar la tarea de planeación y planificación de la estrategia de negocio de acuerdo a cada actividad con el fin de lograr objetivos concretos a corto plazo. La estrategia es el pilar del éxito, de lo contrario, se corre el riesgo de fracasar.

Es importante promover, dentro de los dirigentes de las empresas, la necesidad de formación profesional. Los dirigentes que no hayan concluido sus estudios deben retomarlos y obtener formación empresarial que les permita una realización más profesional de la gestión administrativa y estrategia a la cabeza de sus entidades.

También, se debe motivar a los pequeños empresarios en mantener su actitud emprendedora, de liderazgo, esforzada, comprometida y a seguir mejorando sus capacidades. Incentivar igualmente al personal en aumentar el interés por mejorar su rendimiento y capacidades por medio de la participación en capacitaciones. Las MIPYMET deben mejorar su gestión, su funcionamiento y las capacidades técnicas de todo el talento humano.

Realizar la planeación adecuada y las gestiones necesarias para alcanzar un alto nivel de eficiencia y eficacia operativa. Esto se logra a través de la formulación apropiada de políticas y estrategias de negocios.

Con el propósito de potenciar la toma de decisiones administrativas y estratégicas, se recomienda a los dirigentes establecer mecanismos para la obtención, tratamiento, almacenamiento y análisis de información del entorno global. En la actualidad, las empresas deben ser capaces de tomar los datos a nivel mundial, tomar las mejores prácticas y estrategias e implementarlas para la mejora de su competitividad. Los mecanismos utilizados deben ser capaces de transferir la información relevante a todos los niveles internos.

La actualidad de los negocios hace que la estrategia de trabajar de forma aislada e individualizada esta casi obsoleta, las alianzas estratégicas toman fuerza para el desarrollo y estabilidad de 
las empresas. Dado lo anterior, los dirigentes deben perder el temor a formar enlaces con otros empresarios. Para ello, se espera que busquen apoyo de entes estatales que brinden capacitación e inducción en este tema y se concienticen de los beneficios de la dinámica.

Otra recomendación valiosa es ampliar los horizontes y mantener una mente abierta hacia el nuevo aprendizaje. Los responsables de la gestión administrativa y estratégica deben amparar una participación dinámica hacia los programas y actividades de mejoramiento y capacitación ofrecidos por todas las instituciones del país. Según el MEIC y la CCTIA, la participación de las pymes en este tipo de actividades es muy reducida y no se aprovechan las oportunidades. Se espera que, con la propuesta brindada, el panorama cambie en pro de obtener crecimiento empresarial de todo el sector.

Tanto los empleados como los dirigentes deben seguir capacitándose y actualizando su aprendizaje, el entorno globalizado crea una necesidad de mejoramiento de capacidades permanente. La manera de hacer negocios y las estrategias exitosas se modifican constantemente.

A todos los pequeños empresarios del cantón de Pérez Zeledón y a todos aquellos que quieran incursionar en la entrega de algún bien o producto turístico, se les exhorta a explotar al máximo las oportunidades existentes en un territorio privilegiado de Costa Rica. Pérez Zeledón puede ser convertido en un sitio turístico de altos estándares de calidad en la oferta brindada a los consumidores. De manera estratégica, el cantón se encuentra rodeado por zonas con alta biodiversidad con el potencial de ser desarrollada por los habitantes. En años futuros, se debe convertir al turismo de la zona sur en pilar de la economía y desarrollo del territorio.

Analizando el tema de la innovación, es importante orientar a los empresarios en que la innovación no va en contra del equilibrio eco- lógico. Al contrario, la tecnología actual permite a las empresas incursionar en innovaciones ecológicas, paneles solares, habitaciones que aprovechan ventilación natural, ahorro energético, ahorro de agua, obtención de certificados ecológicos, aprovechamiento de los residuos sólidos, mecanismos de reciclaje, estructuras inteligentes y la ejecución de proyectos de conservación y protección, son algunas de las estrategias innovadoras que pueden ser aplicadas por el sector.

La maximización en el uso de todos los recursos de la organización es otra estrategia de mejoramiento continuo. Se insta a los empleados a reducir al máximo el uso del papel en el desarrollo de su trabajo, en la era digital actual se debe abandonar paulatinamente el excesivo uso del papel. De igual manera, los recursos financieros deben ser planificados adecuadamente para evitar gastos excesivos y despilfarros de dinero. Los dirigentes deben ser responsables de garantizar la estabilidad de la empresa y la de sus empleados.

La globalización no trata únicamente de manejar la información proveniente de fuentes multidireccionales sino, más bien, de transformar esta información de los mercados globales en oportunidades de nuevos negocios, nuevas estrategias, prácticas mejoradas, procesos especializados y en una toma de decisiones estratégica.

Una recomendación importante para las organizaciones es participar de lleno en todas aquellas actividades de capacitación que se dispongan; el estudio fue claro en señalar las falencias en el manejo de idiomas, software e información. De manera estratégica, tienen la posibilidad de establecer enlaces y formar grupos con la necesidad de temas específicos, entregar la solicitud y exigir la solvencia de esa necesidad a instituciones como universidades estatales, INA, MEIC, PROCOMER, ICT, entre muchos otros. 
Se recomienda a las empresas buscar y formalizar alianzas estratégicas con otras pequeñas organizaciones. Esta es una forma eficiente de lograr crecimiento empresarial y desarrollo económico.

\section{CONCLUSIÓN}

Sin duda alguna, el sector turístico es uno de los pilares de la economía del país; por ende se convierte en un elemento relevante para ser constantemente analizado y estudiado. Las empresas turísticas deben preocuparse por llevar a cabo procesos de autoanálisis y evaluación de su quehacer diario y mantenerse a la vanguardia ante los cambios constantes del entorno que es afectado por elementos globalizados.

La eficiente gestión administrativa y estratégica son la clave para que las micro, pequeñas y medianas empresas logren estabilidad organizacional y desarrollo de ventajas competitivas dentro del mercado. El establecimiento de alianzas estratégicas y la puesta en marcha de convenios empresariales son factores a potenciar dentro del sector turismo, ya que ofrecen beneficios de crecimiento y empoderamiento.

Luego del presente estudio, se concluye que las empresas cuentan con alto grado de compromiso y responsabilidad tanto de sus dirigentes como de sus empleados. Esta cualidad hace creer en un panorama alentador que conduzca al desarrollo de nuevas habilidades y competencias organizacionales con las cuales se logre el objetivo de formalización y consolidación de los negocios e ideas innovadoras.

El estudio logra el cumplimiento de los objetivos planteados y conduce a nuevas líneas de investigación en procura de dar seguimiento al crecimiento de las empresas. Se espera generar conciencia acerca de la necesidad de trabajar con las pequeñas empresas de los diferentes sectores económicos del país, ya que uno de los objetivos es ubicarlos en la importancia de estas empresas que generan utilidades y empleos en los cantones donde se localizan. A aquellos dirigentes de dichas empresas, se les exhorta a trabajar en sus negocios, no entrar en letargos y avanzar hacia un crecimiento sostenido.

Para el investigador, son enriquecedores los resultados alcanzados y brindan una guía para establecer, en conjunto con diferentes instituciones públicas y privadas del cantón, una serie de programas y mecanismos para empoderar al sector turístico y establecer sistemas de capacitación dirigida a pequeños dirigentes. Además, se llevarán a cabo acciones para fomentar dentro de la población la generación de nuevas y mejores ideas de negocio.

\section{REFERENCIAS}

Arce, E. J. (2010). Técnicas de servicio para alojamientos Turísticos (1 la ed.). San José, Costa Rica: EUNED.

Barrantes, R. (2010). Investigación: un camino al conocimiento, un enfoque cualitativo y cuantitativo. San José, Costa Rica: EUNED.

Brenes, L. (2008). Gestión estratégica de la microempresa y pequeña empresa turística. San José, Costa Rica: EUNED.

Carbaugh, R. (2009). Economía internacional (12a ed.). México: Cengage Learning Editores, S.A.

Chiavenato, I. (2011). Administración de recursos humanos, el capital humano de las organizaciones (9a ed.). México DF, México: McGraw-Hill.

Daft, R. L. (2011). Teoría y diseño organizacional (10a ed.). México D.F., México: Cengage Learning Editores, S. A. de C.V.

Flores, M. L. (1). Competitividad y liderazgo: elementos vitales para gerentes de unidades de información. E-Ciencias de la información, 3(1), 1-14. doi: 10.15517/ECI.V311.8498

Fred, D. (2008). Conceptos de administración estratégica (11a ed.). México D.F., México: Pearson Educación. 
Hernández, R., Fernández, C., \& Baptista, P. (2010). Metodología de la investigación (5a ed.). México D.F., México: McGraw-Hill.

Instituto Costarricense de Turismo. (2011). Plan nacional de turismo sostenible de Costa Rica 20102016, resumen ejecutivo. Recuperado de http:// www.visitcostarica.com/ict/backoffice/treeDoc/ files/59A5_Resumen\%20del\%20plan\%20\%20 julio\%2020111.pdf

Instituto Nacional de Estadísticas y Censos. (2012). Directorio de unidades Institucionales y Establecimientos 2012. Recuperado de http://www.inec. go.cr/A/MT/Econ\%C3\%B3micos/Directorio\%20 de\%20Establecimientos/Publicaciones/C0/012012/Directorio\%20de\%20Unidades\%20Institucionales\%20y\%20Establecimientos.pdf

Instituto Nacional de Estadísticas y Censos. (2012). Encuesta nacional de hogares julio 2012. Recuperado de http://www.inec.go.cr/A/MS/Encuestas/ Encuesta\%20Nacional\%20de\%20Hogares/Publicaciones/C0/2012/01.\%20Resultados\%20generales\%20ENAHO\%202012.pdf

Laudon, K. C., \& Laudon, J. P. (2008). Sistemas de Información Gerencial: Administración de la empresa digital (10a ed.). México D.F., México: Pearson Educación.

Ministerio de Economía Industria y Comercio. (2002). Ley 8262, Ley de fortalecimiento de las pequeñas y medianas empresas. Recuperado de http://www. pyme.go.cr/media/archivo/normativas/LEY8262_Fortalpymereformas.pdf

Ministerio de Economía Industria y Comercio. (2010). Política nacional de emprendimiento. Administración Chinchilla Miranda 2010-2014. Recuperado de http://www.pyme.go.cr/media/archivo/normativas/PoliticaNacEmpren.pdf

Ministerio de Economía, Industria y Comercio. (2012). Encuesta a establecimientos de la Región Brunca 2011. San José, Costa Rica: MEIC.
Ministerio de Economía, Industria y Comercio. (2012). Entidades financieras colocaron $\$ 242.757$ millones en crédito para Pymes, I sem 2012. Recuperado de http://www.pyme.go.cr/noticia.php?|D=50

Ministerio de Economía, Industria y Comercio. (2012). Red de apoyo a PYME. Recuperado de http://www. meic.go.cr/index.php?option=com_content\&view $=$ article\&id $=143 \& \mid$ temid $=170$

Ministerio de Economía, Industria y Comercio. (2013). Estado de situación de las PYMEs en Costa Rica. Recuperado de http://reventazon.meic.go.cr/informacion/estudios/2013/pyme/indicadores/pcp37-13.pdf

Robbins, S. P., \& Coulter, M. (2011). Administración (3a ed.). México D.F., México: Pearson Educación.

Tarantino, S. (16 de noviembre, 2012). ¿Gerencia o Gestión?, ¿Son sinónimos? Recuperado de http:// www.degerencia.com/articulo/gerencia-o-gestion-son-sinonimos

Ulate, I., \& Vargas, E. (2012). Metodología para elaborar una tesis como trabajo final de graduación: para optar por el grado de licenciatura en la Escuela de Ciencias de la Administración. San José, Costa Rica: EUNED

Universidad Estatal a Distancia, Observatorio de Micro, pequeñas y medianas empresas. (2012). Boletín de prensa, Estado Nacional de las MIPYMES 2012. San José, Costa Rica: Autor.

Vecino, J. M. (22 de febrero, 2011). Pilares de una gestión gerencial relevante. Recuperado de http://www. degerencia.com/articulo/pilares-de-una-gestion-gerencial-relevante

Recibido: 26 de setiptiembre de 2017 Aceptado: 20 de julio de 2018 